\title{
Ocorrência de Plantas não Nativas e Exóticas em Áreas Restauradas de Campos Rupestres ${ }^{1}$
}

\author{
Occurrence of Non-Native and Exotic Plants in Restored Areas of Rupestrian Grasslands
}

\author{
FERNANDES, G.W. ${ }^{2,3}$, SANTOS, R. ${ }^{2}$, BARBOSA, N.P.U. ${ }^{2,4}$, ALMEIDA, H.A. ${ }^{2}$, CARVALHO,V. ${ }^{2}$ e \\ ANGRISANO, P. ${ }^{2}$
}

\begin{abstract}
RESUMO - A invasão por espécies de plantas não nativas representa um enorme problema para projetos de restauração ambiental. Estas espécies têm causado muitas vezes o fracasso do processo de restauração, a perda de estoques nativos, prejuízos econômicos e, certamente, sociais. O objetivo do presente trabalho foi listar e avaliar a ocorrência de espécies não nativas em decorrência do asfaltamento da MG-010 em áreas restauradas nos campos rupestres da cordilheira do Espinhaço, Serra do Cipó, Brasil. Foram encontradas 23 espécies de plantas não nativas invadindo as áreas restauradas. Entre essas espécies, destacam-se as leguminosas Cajanus cajan, Chamaecrista flexuosa, Crotalaria pallida, Crotalaria spectabilis e Mimosa pigra e, entre as gramimeas, Andropogon bicornis, A. leucostachyus, Melinis repens, M. minutiflora, Paspalum paniculatum e Urochloa brizantha. A invasão das áreas restauradas, bem como a das bordas da rodovia, por essas espécies está relacionada à melhoria dos solos ao longo das rodovias causada por técnicas que utilizam uma mistura de calcário no preparo do leito estradal. A falta de um programa de monitoramento e gestão das áreas restauradas, bem como das unidades de conservação federal na qual estão inseridas, é outro fator que resulta em falhas no processo de restauração, colocando em risco toda a biota regional.
\end{abstract}

Palavras-chave: cerrado, invasão biológica, impacto ambiental, Serra do Espinhaço, Serra do Cipó.

\begin{abstract}
Non-native plant species invasion significantly represents a problem to projects on environment restoration. Such species have often been associated with the failure of restoration processes, the loss of local inputs, economic issues and, certainly, social losses. This present work aimed at listing and assessing the occurrence of non-native species resulting from the pavement work conducted on route MG-O1O in restored areas of rupestrian grassland vegetation along the Espinhaço ridge, on the Cipó range, in Brazil. A total of 23 non-native plant species were found to invade the restored areas. Among such species, we may highlight the legumes Cajanus cajan, Chamaecrista flexuosa, Crotalaria pallida, Crotalaria spectabilis, and Mimosa pigra; and among the invasive weeds, Andropogon bicornis, A. leucostachyus, Melinis repens, M. minutiflora Paspalum paniculatum and Urochloa brizantha. Such species invasion in restored areas, as well in highway roadside, is associated with soil improvements along the highways, which use a common technique that includes limestone-soil mixture in pavement bed preparation. The lack of monitoring and management of restored areas, as well as of the national conservation units where they are located, is another factor that hinders the restoration process, endangering the unique local flora.
\end{abstract}

Keywords: biological invasion, Brazilian inland vegetation, environmental impact, Serra do Espinhaço, Serra do Cipó.

Recebido para publicação em 10.2.2015 e aprovado em 31.3.2015.

2 Universidade Federal de Minas Gerais, Belo Horizonte-MG Brasil; <gw.fernandes@gmail.com>; ${ }^{3}$ Stanford University, Stanford, CA 94305 USA. ${ }^{4}$ Centro de Bioengenharia de Espécies Invasoras (CBEIH), Belo Horizonte-MG Brasil. 


\section{INTRODUÇÃO}

A introdução de espécies não nativas em ecossistemas naturais representa, atualmente, uma das maiores ameaças à perda de diversidade biológica do planeta (Simberloff, 2003). Os episódios de invasão atuam sinergicamente com outras causas das mudanças globais, como a destruição de habitats e a poluição (Fuller et al., 1999; Mack et al., 2000), e causam perdas irreparáveis nos ecossistemas. Além da perda de estoques nativos, as espécies não nativas e invasoras causam grandes prejuízos econômicos. Há mais de 15 anos, esses prejuízos foram estimados em 50 bilhões de dólares ao ano no Brasil (considerando os gastos com a prevenção e mitigação para a agropecuária e saúde humana) (Pimentel et al., 2001).

Os estudos sobre a presença de plantas não nativas nos frágeis ecossistemas montanhosos ainda são incipientes. Os primeiros estudos de relevância foram iniciados a partir de 2005 pela Mountain Invasion Research Network (MIREN), os quais incluíram seis regiões montanhosas em todo o mundo (noroeste pacífico dos Estados Unidos, Alpes suíços, Andes chilenos, Alpes australianos, Havaí e as Ilhas Canárias, na região da Espanha) (Dietz et al., 2006; Küffer et al., 2008). Uma revisão sobre as invasões de plantas não nativas em ecossistemas montanhosos, realizada pela MIREN, identificou quase 1.500 táxons de plantas invasoras ou naturalizadas em todo o mundo. Ameaças a esses ecossistemas representam grandes perdas biológicas, sociais e econômicas, já que muitas dessas regiões são hotspots de biodiversidade com grande número de espécies endêmicas ameaçadas, são bases das fontes de água das planícies e possuem paisagens que são atrações para o turismo e recreações (Martinelli, 2007).

Estudos recentes indicam aumento significativo no risco de invasões biológicas por plantas não nativas nos diversos ecossistemas de montanha em todo o mundo (Rouget et al., 2003; Baret et al., 2006). As causas são variadas, mas sobretudo relacionadas às alterações climáticas e às drásticas mudanças no uso do solo (Pauchard et al., 2009; Barbosa et al., 2010). Perturbações antropogênicas aumentam a suscetibilidade das comunidades naturais à invasão (Mack et al., 2000). Perturbações geradas pelo fogo, por exemplo, podem prover vantagens competitivas iniciais para plantas não nativas, pois o fogo pode causar aumento na disponibilidade de nutrientes por um tempo curto (Coutinho, 1990; Nardoto et al., 2006). Uma vez estabelecida a dominância das espécies não nativas invasoras, o estabelecimento de outras espécies competidoras no processo de sucessão natural pode ficar inibido em virtude da crescente limitação dos recursos (Hughes \& Vitousek, 1993). Embora Küffer et al. (2008) tenham indicado que condições climáticas adversas e o isolamento humano seriam fatores que tornariam os ecossistemas montanhosos relativamente resistentes às invasões de espécies não nativas, o aumento das ocupações humanas em regiões montanhosas, paralelamente à construção de vias pavimentadas de acesso, potencializa a introdução e o estabelecimento de espécies não nativas nesses ambientes (Viana et al., 2005; Küffer et al., 2008). Os ecossistemas montanhosos estão se tornando tão suscetiveis às invasões quanto outras áreas historicamente invadidas, e a tendência é piorar, devido ao cenário de mudanças climáticas. Um estudo realizado por Kgope et al. (2010) constatou que o aumento de $\mathrm{CO}^{2}$ atmosférico aumenta a competitividades de plantas lenhosas, fazendo com que estas sejam mais eficientes na competição em relação às plantas que evoluíram sob baixas emissões de $\mathrm{CO}^{2}$. Estes autores postularam um evento de invasão dos ambientes ricos em carbono das montanhas da África do Sul pelas plantas não nativas lenhosas já instaladas na região (Kgope et al., 2010). Predições similares podem ser feitas para os já impactados campos rupestres (Sá et al., 2014).

A construção de rodovias é um processo que apresenta profundo impacto no meio ambiente, pois tanto suprime quanto fragmenta as formações vegetais. Se realizada de forma errônea, como é o caso geral no Brasil, pode ampliar várias vezes os danos ambientais através do carreamento de material alóctone para o ambiente adjacente, com consequente impacto nas espécies nativas e destruição de seus habitats. Em montanhas, esses processos podem resultar em grandes perdas devido a fragilidade dos habitats, raridade local das 
espécies, baixa resiliência e, ainda, grande sintonia entre as espécies e o ambiente (Negreiros et al., 2011). Tilman (1993, 1997) afirmou que a construção e a manutenção das rodovias modificam as condições nutricionais do solo adjacente às vias, facilitando o estabelecimento de espécies que precisam de condições nutricionais e hídricas semelhantes às do novo solo para se estabelecer. Além disso, a eliminação da vegetação nativa cria áreas seguras para germinação das sementes das espécies introduzidas (Lonsdale \& Lane, 1994; Greenberg et al., 1997; Trombulak \& Frissel, 2000; Christen \& Matlack, 2006). No caso de ambientes marcados pelas condições adversas provocadas pelo baixo teor nutricional dos solos e/ou excesso de elementos tóxicos, como o alumínio, a exemplo dos campos rupestres quartzíticos e ferruginosos na cadeia da Serra do Espinhaço no Sudeste brasileiro e no Pará, essas modificações podem resultar em drásticas mudanças e favorecer ainda mais as invasões.

Barbosa et al. (2010) mostraram que durante as obras de asfaltamento da rodovia MG-010, na Serra do Cipó, em Minas Gerais, a cobertura da via com uma mistura de cimento e terra ("cimento-solo") resultou no tamponamento do efeito tóxico do alumínio nos solos (Negreiros et al., 2009), favorecendo a entrada e o sucesso de espécies ruderais tanto nativas quanto não nativas, incluindo inúmeras espécies sabidamente exóticas. Estas espécies têm formado "verdadeiros exércitos" prontos para colonizar novas áreas alteradas, à medida que estas têm surgido (Fernandes \& Barbosa, 2013). Os estudos têm mostrado mais uma vez que as rodovias atuam como corredor ou facilitador da entrada de espécies invasoras que podem colocar em risco a biodiversidade e serviços ecossistêmicos (Barbosa et al., 2010). A vegetação predominante na borda oeste da Serra do Cipó é representada pelos campos rupestres. O aumento constante das atividades humanas dentro desta região, tais como a mineração, a construção de estradas, o tráfego intenso de veículos, o estabelecimento de pastagens, o turismo e os incêndios periódicos, tem sido as principais causas de invasão por espécies não nativas (Fernandes et al., 2014) (Figuras 1, 2, 3 e 4).
Em 2010, nove áreas degradadas pelas obras de asfaltamento da rodovia MG 10 foram restauradas pelo DER-MG (Departamento Estadual de Rodagem do Estado de Minas Gerais), utilizando-se espécies nativas da flora local. Os serviços de restauração das áreas degradadas foram completados em janeiro de 2012 e, a seguir, abandonados sem que se tenha elaborado nenhum plano de monitoramento. Consequentemente, muitas espécies que haviam colonizado as margens da rodovia foram capazes de se dispersar e invadir as áreas em restauração. Diante da iminente ameaça à riqueza e do alto grau de endemismo
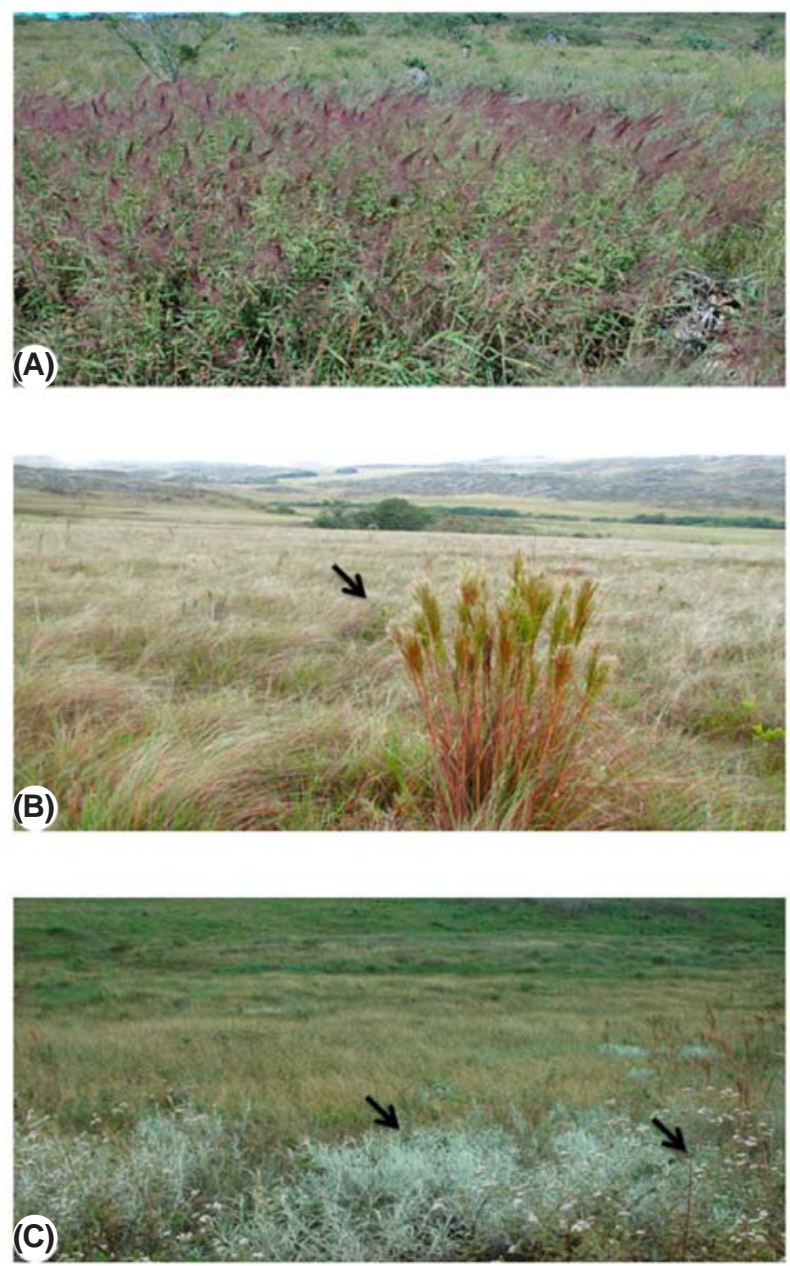

Figura 1 - Início de invasão do campo rupestre por espécies de gramíneas exóticas, nativas e espécies herbáceas a partir da rodovia MG 10. (A) Início de invasão do campo rupestre pela gramínea exótica Melinis minutiflora. (B) Início de invasão do campo rupestre pela gramínea nativa Andropogon bicornis. (C) Início de invasão do campo rupestre pelas espécies Achyrocline satureoides e Ageratum fastigiatum. 
da flora da Serra do Cipó, em associação ao risco da alteração da estrutura da comunidade de plantas nativas e consequente perda dos serviços ambientais, este trabalho teve como objetivo listar pela primeira vez as espécies não nativas nas áreas restauradas de campo rupestre.

\section{MATERIAL E MÉTODOS}

As coletas foram realizadas entre os meses de janeiro e maio de 2013 em 9 áreas restauradas às margens da rodovia MG-010 (a partir do $\mathrm{km} 106, \mathrm{~W}^{\circ} 3^{\circ} 35^{\prime} 55^{\prime} / \mathrm{S} 19^{\circ} 17^{\prime} 35,4^{\prime \prime}$, até o km $\left.126, \mathrm{~W} 43^{\circ} 34^{\prime} 00^{\prime \prime} / \mathrm{S} 19^{\circ} 17^{\prime} 25^{\prime \prime}\right)$. A rodovia MG-010 liga os municípios de Lagoa Santa e Conceição do Mato Dentro, cruzando a Área de Proteção Ambiental (APA) Morro da Pedreira, e atravessa um pequeno trecho no limite noroeste do Parque Nacional da Serra do Cipó (Barbosa et al., 2010). Localiza-se ao sul da cordilheira do Espinhaço, que possui formações rochosas quartzíticas, e se prolonga por cerca de $1.100 \mathrm{~km}$ com largura entre $50 \mathrm{e}$ $100 \mathrm{~km}$ e altitudes superiores a $800 \mathrm{~m}$.

A cobertura vegetal na Serra do Cipó é muito diversificada, variando principalmente conforme o solo e a altitude (Carvalho et al., 2012). A área de estudo varia em altitude: entre 1.000 e $1.300 \mathrm{~m}$ acima do nível do mar. Os solos compreendidos neste trecho são rasos, arenosos, ácidos, pobres em nutrientes e matéria orgânica, podendo ser finos ou cascalhentos, e formados a partir da desagregação da rocha-mãe (Benites et al. 2007; Negreiros et al., 2011). A vegetação é baixa, com alguns arbustos e pequenas árvores, xerófila e esclerófila, apresentando matas de galeria nas proximidades de cursos de água. O clima é estacional, com verões úmidos de sete a oito meses, invernos secos de três a quatro meses e precipitação anual em torno de $1.500 \mathrm{~mm}$, em média (Madeira \& Fernandes, 1999).

\section{Amostragem da vegetação}

Para a amostragem da vegetação não nativa, foram utilizados quatro transectos de 10 metros de comprimento por 10 metros de largura, totalizando $400 \mathrm{~m}^{2}$ por área $($ total $=$ $3.600 \mathrm{~m}^{2}$ ). Os espécimes coletados foram herborizados e identificados por taxonomistas e colocados na coleção do Laboratório de Ecologia Evolutiva \& Biodiversidade da Universidade Federal de Minas Gerais.

Neste artigo foram adotadas algumas definições sobre o status invasor das espécies, conforme a seguir. Espécie invasora seria aquela espécie oriunda de certa região que penetra e se aclimata em outra, onde não era encontrada antigamente, prolifera sem controle e passa a representar ameaça para espécies nativas e para o equilíbrio dos ecossistemas. Espécie ruderal é a designação dada às espécies vegetais que são predominantemente encontradas em ambientes fortemente perturbados pela ação humana, como cascalheiras, depósitos de entulho, aterros, margens de estradas, etc. Por extensão, designam-se por "plantas ruderais", ou por "vegetação ruderal", as espécies e as comunidades vegetais típicas desses ambientes (Hulme, 2006). Espécies naturalizadas são plantas exóticas que se reproduzem consistentemente e que mantêm populações estáveis ao longo de muitos ciclos de vida sem intervenção humana direta (ou apesar dela) e não invadem necessariamente ecossistemas naturais, seminaturais ou antropizados (Rejmánek et al., 2005; Richardson \& Pyšek, 2008). Finalmente, a espécie exótica seria aquela introduzida fora de sua área de distribuição natural, passada ou presente, que possa levar à reprodução (D’Antonio \& Meyerson, 2002).

Finalmente, buscou-se pela primeira vez relacionar a ocorrência das espécies nos campos rupestres, em relação às outras formações vegetais no País, e verificar a existência de estudos que constatam a ocorrência das espécies como sendo ruderais, invasoras e exóticas. Essa tarefa foi necessária após constatação de que muitas espécies exóticas extremamente nocivas ao meio ambiente haviam sido categorizadas como nativas pelo Jardim Botânico do Rio de Janeiro (<http:/ / www.jbrj.gov.br/>; acesso em: 20 jan. 2014). Assim, foi observada a origem das espécies de acordo com os registros do Jardim Botânico do Rio de Janeiro, sua ocorrência prévia nos campos rupestres da região da Serra do Cipó de acordo com a publicação de referência de Giuliette et al. (1987) e, ainda, realizou-se uma 
busca intensa no Web of Science (1945-2014), Sciello e Scirus sobre o registro da espécie como nativa, ruderal, invasora ou exótica invasora.

\section{RESULTADOS E DISCUSSÃO}

Foram identificadas 12 famílias e 79 espécies de plantas colonizando a área total de $3.600 \mathrm{~m}^{2}$, com exceção das espécies de plantas nativas introduzidas no processo de restauração (principalmente: Baccharis dracunculifolia, B. platypoda, Collaea cipoensis, Coccoloba cereifera, Chamaecrista semaphora, Calliandra fasciculata, C. dysantha, Actinocephalus bongardii, Diplusoson hirsutus, Diplusodon orbicularis, Comolia sertularia, Jacaranda caroba, Mimosa foliolosa, Mimosa bombycina, Mimosa maguirey, Eremanthus erythropappus, Tibouchina grandulosa, Tibouchina candolleana, Tibouchina heteromala, Cecropia pachystachya, Marcetia taxifolia, Lavoisiera campos-portoana, L. francavilana, Dalbergia miscolobium, Kielmeyera regalis, $K$. petiolaris e Stryphnodendron adstringens). As famílias com maior riqueza de espécies foram Poaceae (34 spp.), Fabaceae (21 spp.) e Asteraceae (11 spp.), que, juntas (66 spp.), representaram cerca de $85 \%$ de todas as espécies encontradas (79 spp.). As espécies listadas foram reconhecidas na literatura como de origem exótica (6 espécies), invasoras (16 espécies), daninhas (7 espécies) e ruderais (10 espécies) (Tabela 1). Dessa forma, foram listadas 39 espécies de plantas com potencial invasor nas áreas restauradas, enquanto nenhum relato foi encontrado para cinco espécies. Diante disso, $50 \%$ ou mais das espécies encontradas neste estudo colonizando as áreas restauradas (79 spp.) oferecem algum perigo ao projeto de restauração ambiental e/ou ao campo rupestre. Em relação ao intenso inventário realizado por Giuliette et al. (1987), 49 das 79 espécies não haviam sido reportadas previamente, ou seja, $62 \%$ são registros de nova ocorrência nos últimos 25 anos apenas numa área de $3.600 \mathrm{~m}^{2}$.

A família que apresentou maior número de novas ocorrências no campo rupestre da Serra do Cipó foi Poaceae: 16 das 34 espécies listadas (ca. 47\%) são consideradas novas ocorrências para os campos rupestres da Serra do Cipó, com muitas delas sendo espécies altamente nocivas que ameaçam direta ou indiretamente a integridade dos campos rupestres (Tabela 1). O segundo grupo de maior destaque é representado pela família Fabaceae, com 15 das 21 espécies mensuradas consideradas novas ocorrências para os campos rupestres da Serra do Cipó, o que representa cerca de $71 \%$ das espécies listadas de Fabaceae (Tabela 1). O terceiro grupo de maior destaque é representado pela família Asteraceae, com 9 das 11 espécies registradas consideradas novas ocorrências para os campos rupestres da Serra do Cipó (82\% das espécies listadas nesta família) (Tabela 1). Em resumo, 62\% das espécies do grupo mais representativo das plantas que colonizaram as áreas restauradas (famílias Poaceae, Fabaceae e Asteraceae $=66$ espécies) são de novas ocorrências para os campos rupestres da região da Serra do Cipó.

O alto número de espécies da família Poaceae com potencial invasor encontrado neste estudo provavelmente está relacionado tanto à grande utilização desta família na formação de pastagens em toda a região, como também à invasão natural ou mesmo introdução intencional. O manejo exacerbado de gramineas para a alimentação animal abre espaço para a introdução de espécies não nativas invasoras, sobretudo as de origem africana, como Urochloa brizantha e Melinis minutiflora. Curiosamente, estas espécies são listadas como naturalizadas pelo Jardim Botânico do Rio de Janeiro (Tabela 1). Gramineas africanas são muito utilizadas para esse fim, pois são invariavelmente mais palatáveis para os animais de criação, possuem maior produtividade e são mais resistentes ao pisoteio pelo gado do que as espécies nativas da América (Parsons, 1972). Além disso, gramíneas não nativas podem se dispersar muito facilmente (anemocoria); são, frequentemente, muito competitivas; e possuem maiores taxas fotossintéticas, métodos mais eficientes de utilização de nutrientes e, ainda, maior eficiência no uso de nitrogênio em relação às gramíneas nativas (Silva \& Haridasan, 2007). Estas gramíneas têm-se espalhado por grandes áreas e, consequentemente, substituído as espécies nativas, como mostrado de maneira bastante clara por 


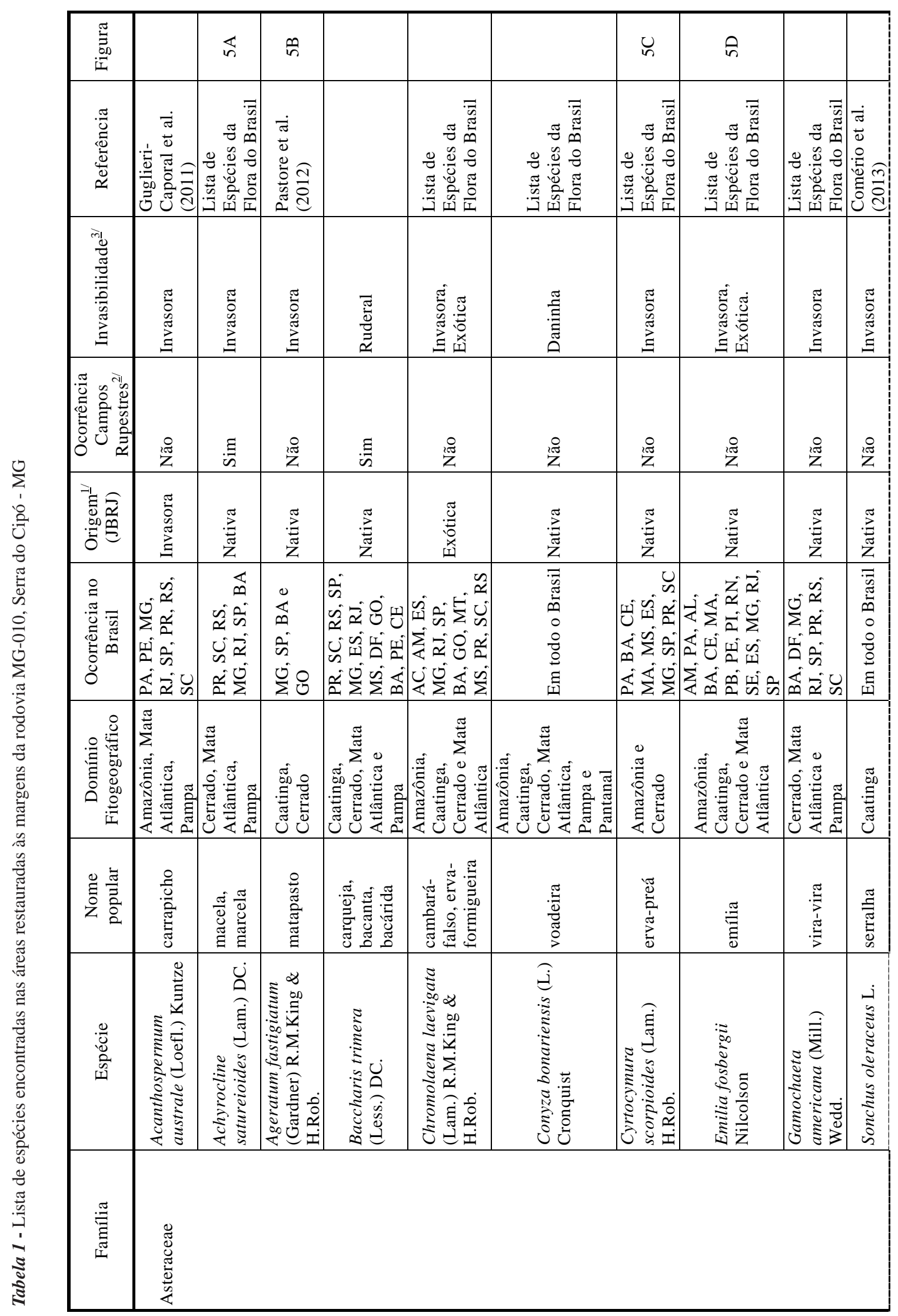




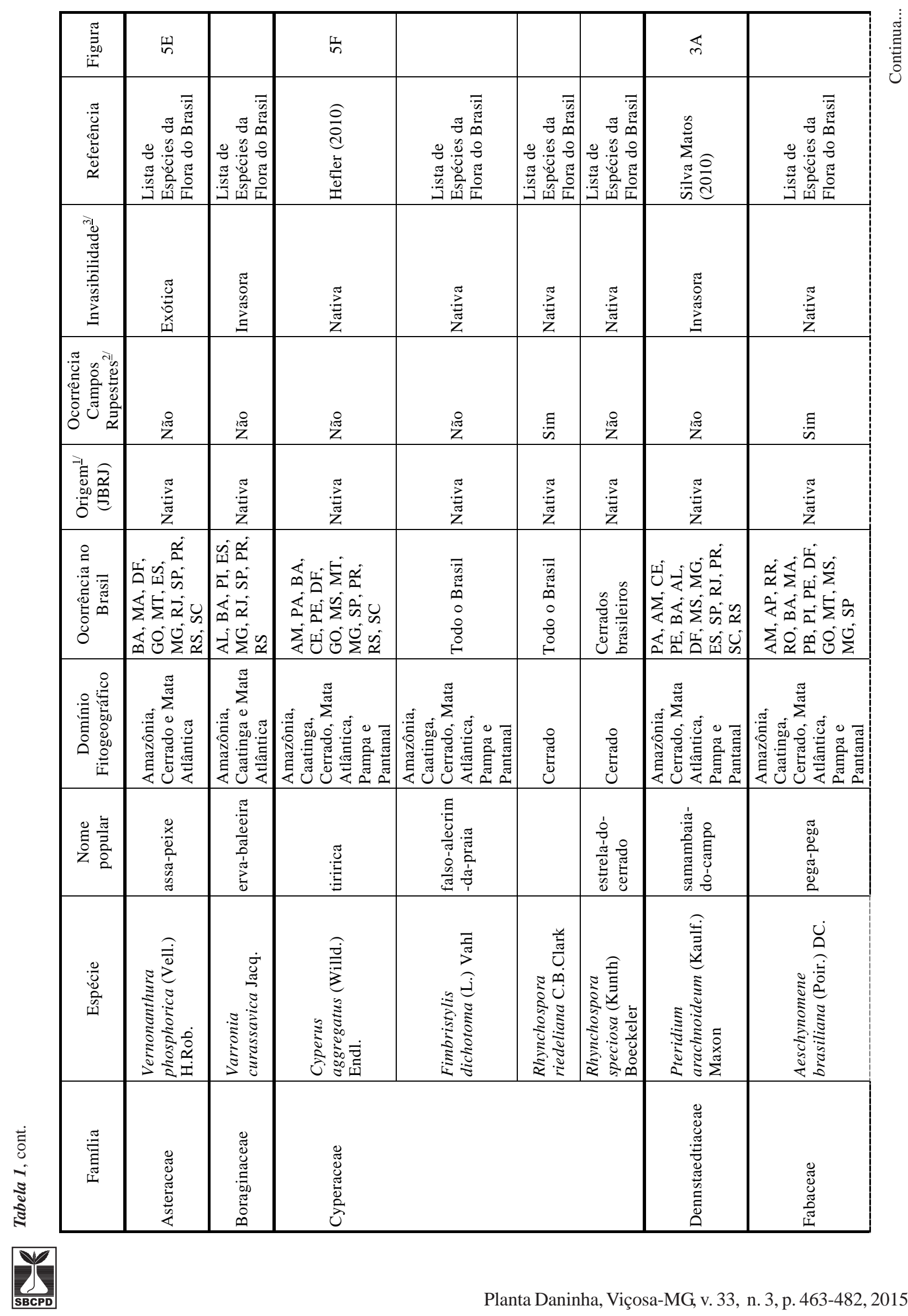




\begin{tabular}{|c|c|c|c|c|c|c|c|c|}
\hline 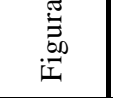 & $\stackrel{m}{m}$ & & & & & & u & लि \\
\hline 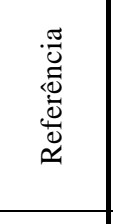 & 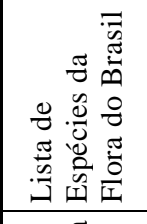 & 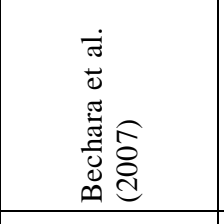 & 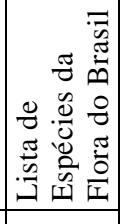 & 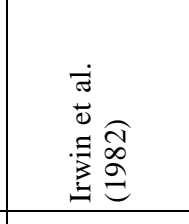 & 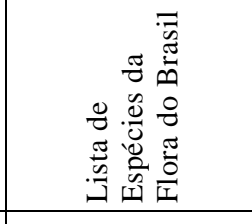 & 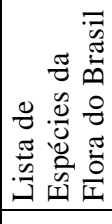 & 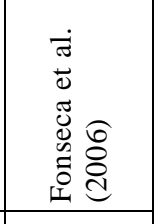 & 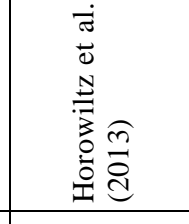 \\
\hline 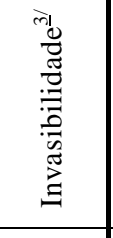 & 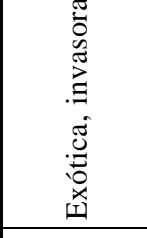 & 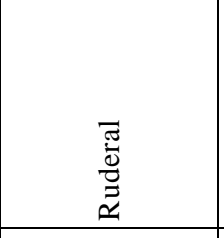 & $\begin{array}{l}\stackrel{0}{\widetilde{Z}} \\
Z\end{array}$ & $\begin{array}{l}\stackrel{\pi}{\Xi} \\
Z\end{array}$ & $\stackrel{\overbrace{}}{\pi}_{Z}^{\pi}$ & 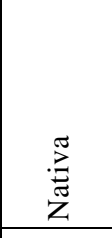 & 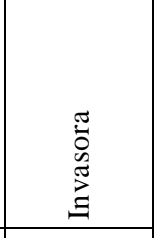 & 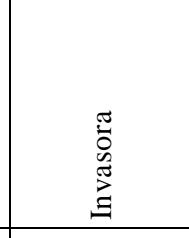 \\
\hline 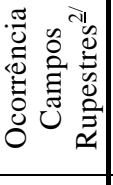 & 党 & 慁 & 完 & 思 & 思 & 离 & $\begin{array}{l}2 \pi \\
z\end{array}$ & 完 \\
\hline 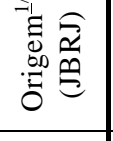 & 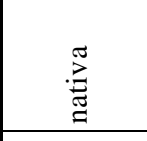 & $\underset{\overbrace{}}{\stackrel{\pi}{\pi}}$ & $\begin{array}{l}\stackrel{\pi}{\pi} \\
Z\end{array}$ & $\stackrel{\overbrace{}}{\pi}_{Z}^{\pi}$ & $\begin{array}{l}\stackrel{\pi}{\pi} \\
Z\end{array}$ & $\begin{array}{l}\stackrel{\pi}{\pi} \\
Z\end{array}$ & $\begin{array}{l}\stackrel{\pi}{\pi} \\
Z\end{array}$ & 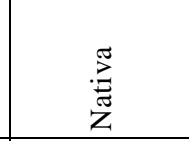 \\
\hline 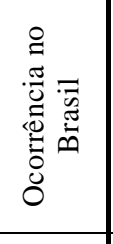 & 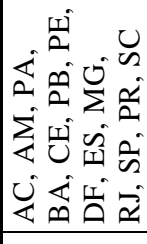 & 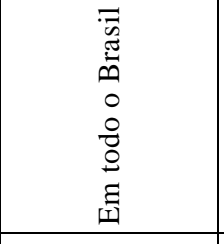 & $\begin{array}{l}\sum_{1}^{0} \\
\text { Di } \\
\text { 市 }\end{array}$ & 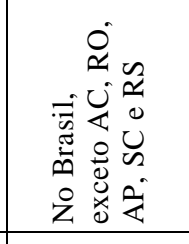 & 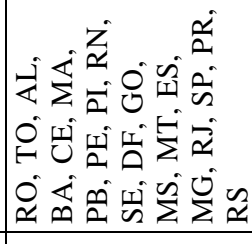 & $\begin{array}{l}\sum_{\infty}^{0} \\
\dot{\infty}\end{array}$ & 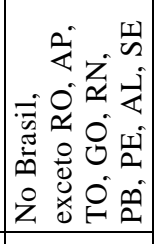 & 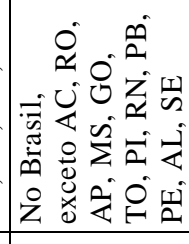 \\
\hline 赵 & 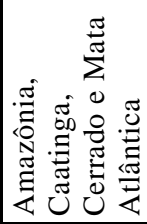 & 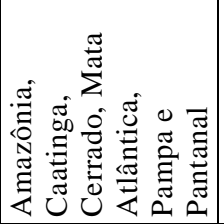 & 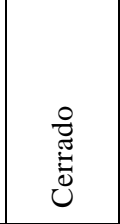 & 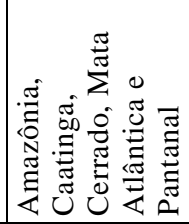 & 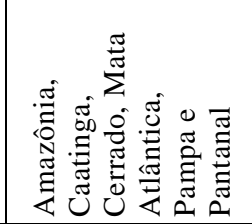 & 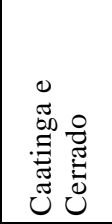 & 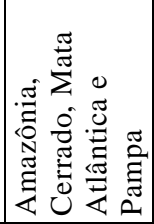 & 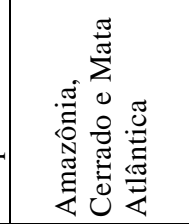 \\
\hline 咅 & 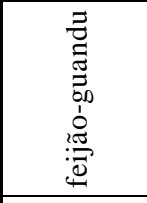 & 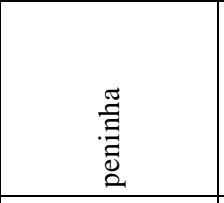 & & 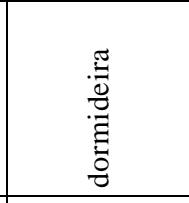 & 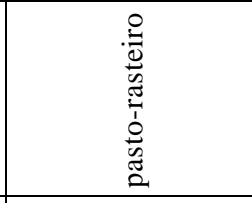 & & 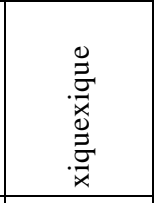 & 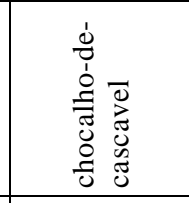 \\
\hline 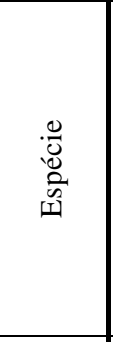 & 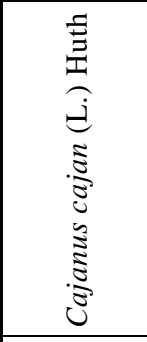 & 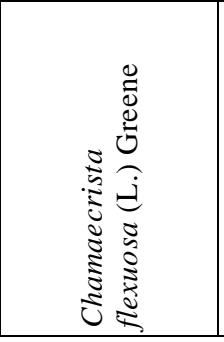 & 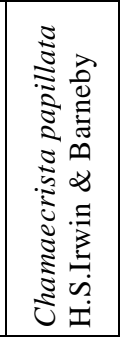 & 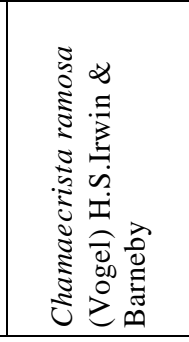 & 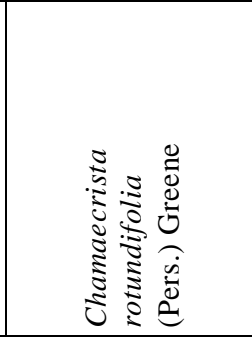 & 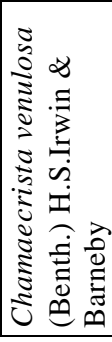 & $\begin{array}{l}0 \\
0 \\
0 \\
0 \\
0 \\
0 \\
0 \\
0 \\
0 \\
0 \\
0 \\
0 \\
0 \\
0 \\
0\end{array}$ & 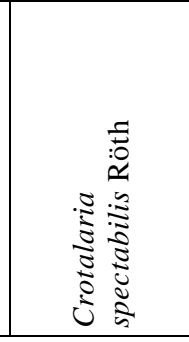 \\
\hline 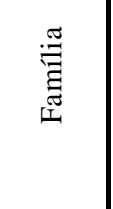 & 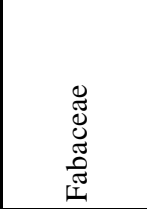 & & & & & & & \\
\hline
\end{tabular}




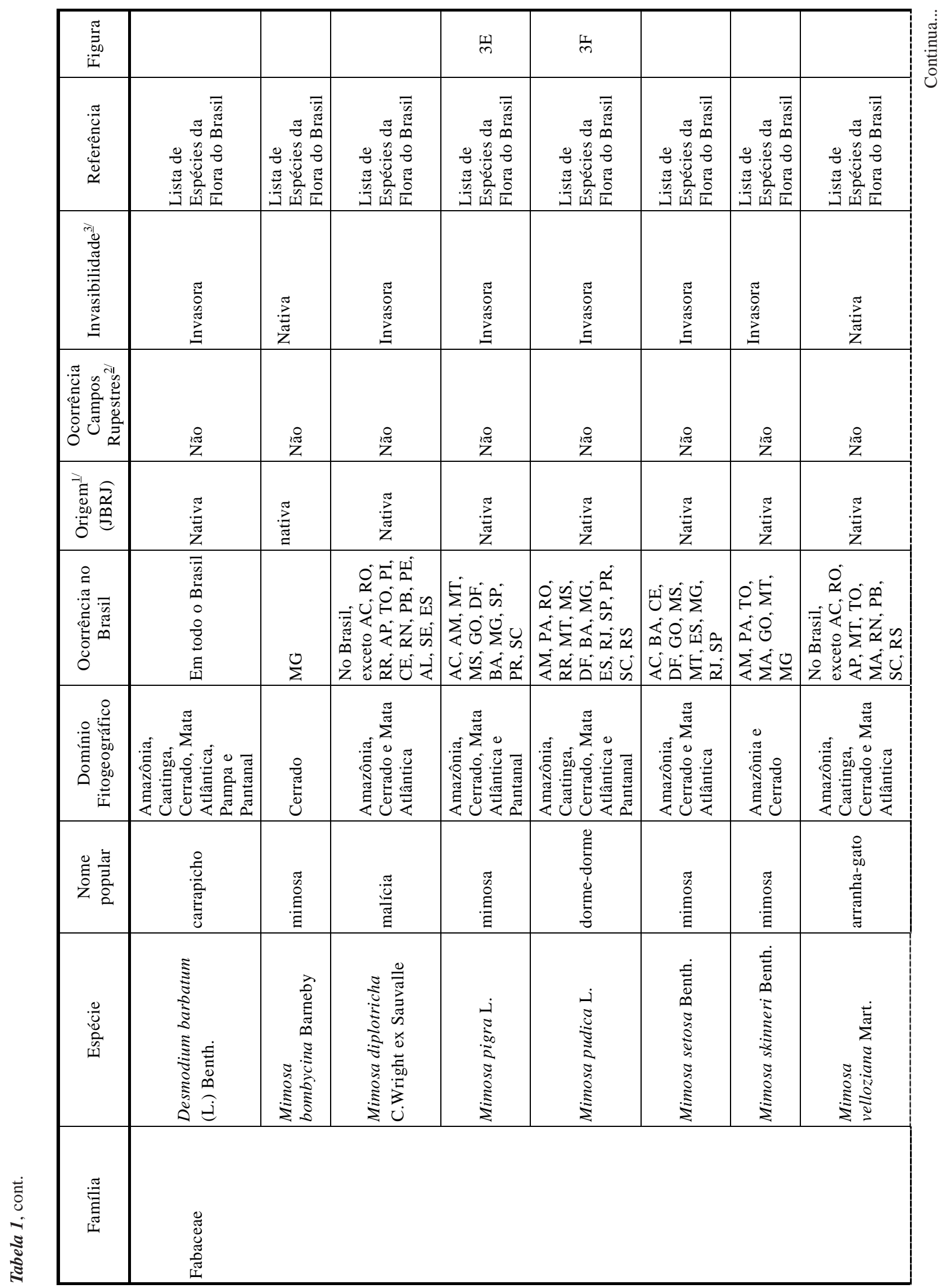




\begin{tabular}{|c|c|c|c|c|c|c|c|}
\hline 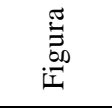 & & & 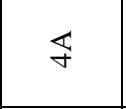 & & & $\mathscr{f}$ & \\
\hline 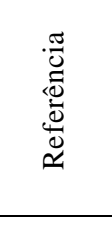 & 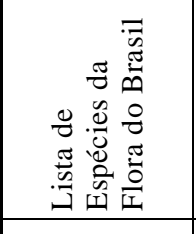 & 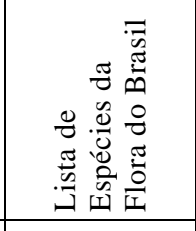 & 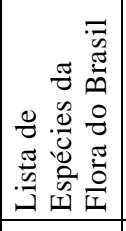 & 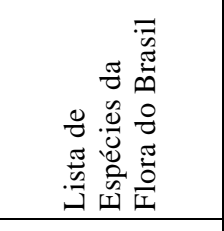 & 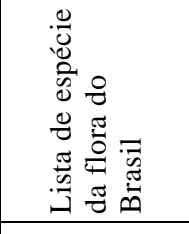 & 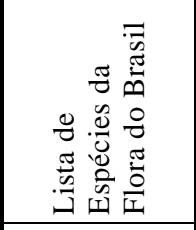 & 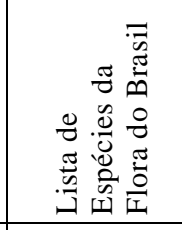 \\
\hline 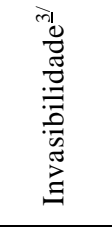 & 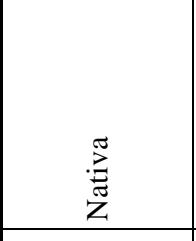 & $\stackrel{\widetilde{Z}}{\stackrel{\pi}{Z}}$ & 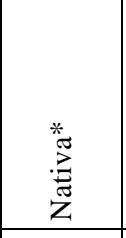 & 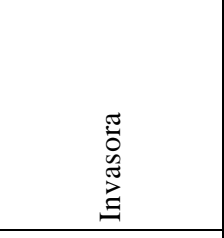 & 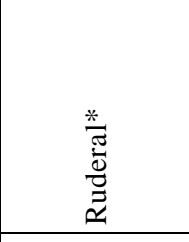 & 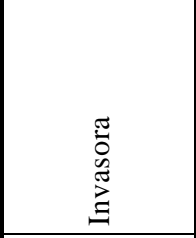 & $\begin{array}{l}\widetilde{a} \\
0 \\
0 \\
\stackrel{0}{\Xi} \\
\end{array}$ \\
\hline 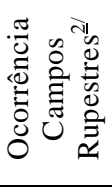 & $\underset{2}{\stackrel{0}{Z}}$ & 疍 & 慁 & 貝 & $\begin{array}{l}\stackrel{0}{\pi} \\
\end{array}$ & 具 & $\underset{殳}{2 \pi}$ \\
\hline 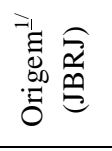 & $\stackrel{\pi}{\stackrel{\pi}{\pi}}$ & $\underset{\stackrel{Z}{Z}}{\stackrel{\pi}{Z}}$ & $\begin{array}{l}\stackrel{\pi}{Z} \\
\stackrel{\mathbb{E}}{Z} \\
\end{array}$ & $\begin{array}{l}\stackrel{\pi}{\mathbb{E}} \\
Z\end{array}$ & $\begin{array}{l}\stackrel{\pi}{ \pm} \\
Z \\
Z\end{array}$ & 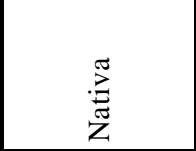 & 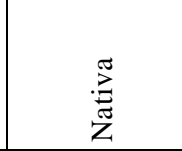 \\
\hline 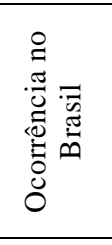 & 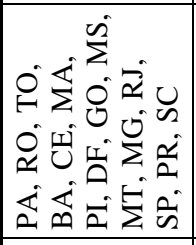 & 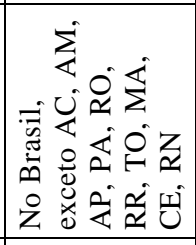 & 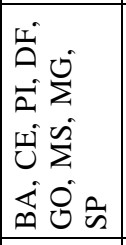 & 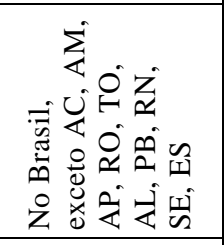 & 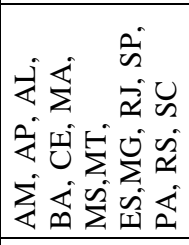 & 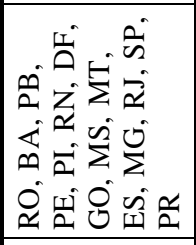 & 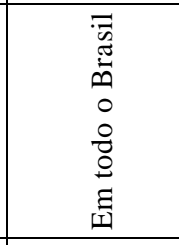 \\
\hline . & 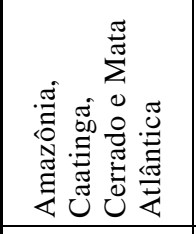 & 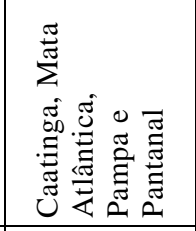 & 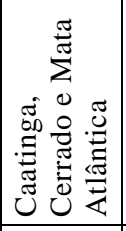 & 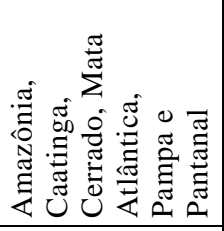 & 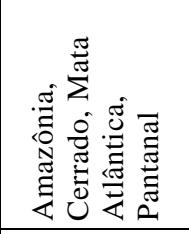 & 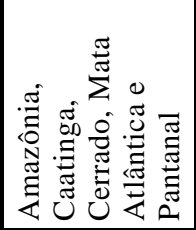 & 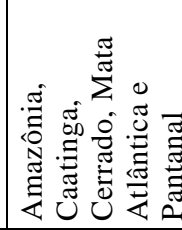 \\
\hline 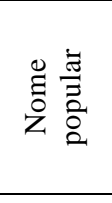 & 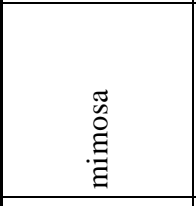 & 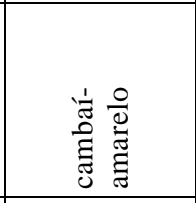 & 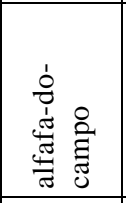 & 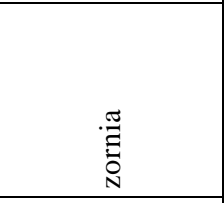 & 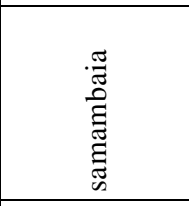 & 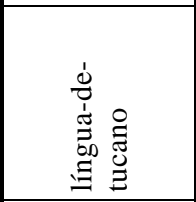 & 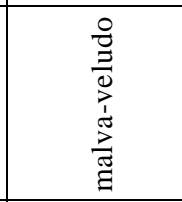 \\
\hline 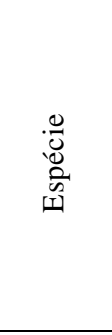 & 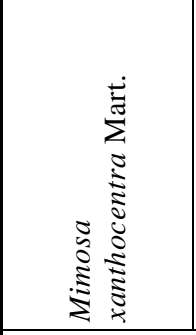 & 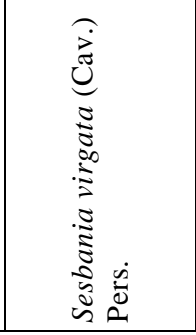 & 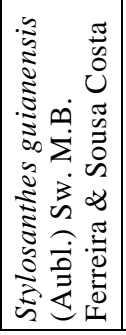 & 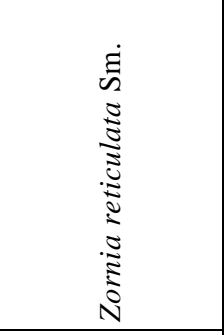 & 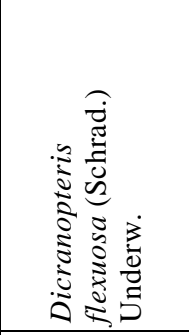 & 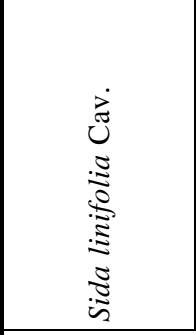 & 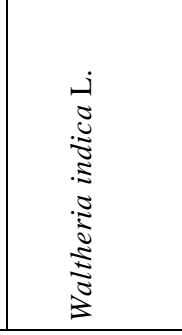 \\
\hline 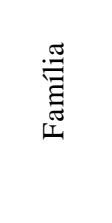 & 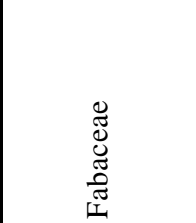 & & & & 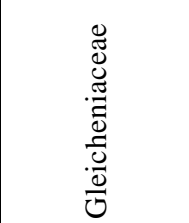 & 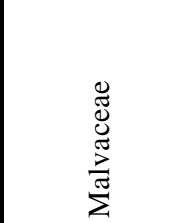 & \\
\hline
\end{tabular}




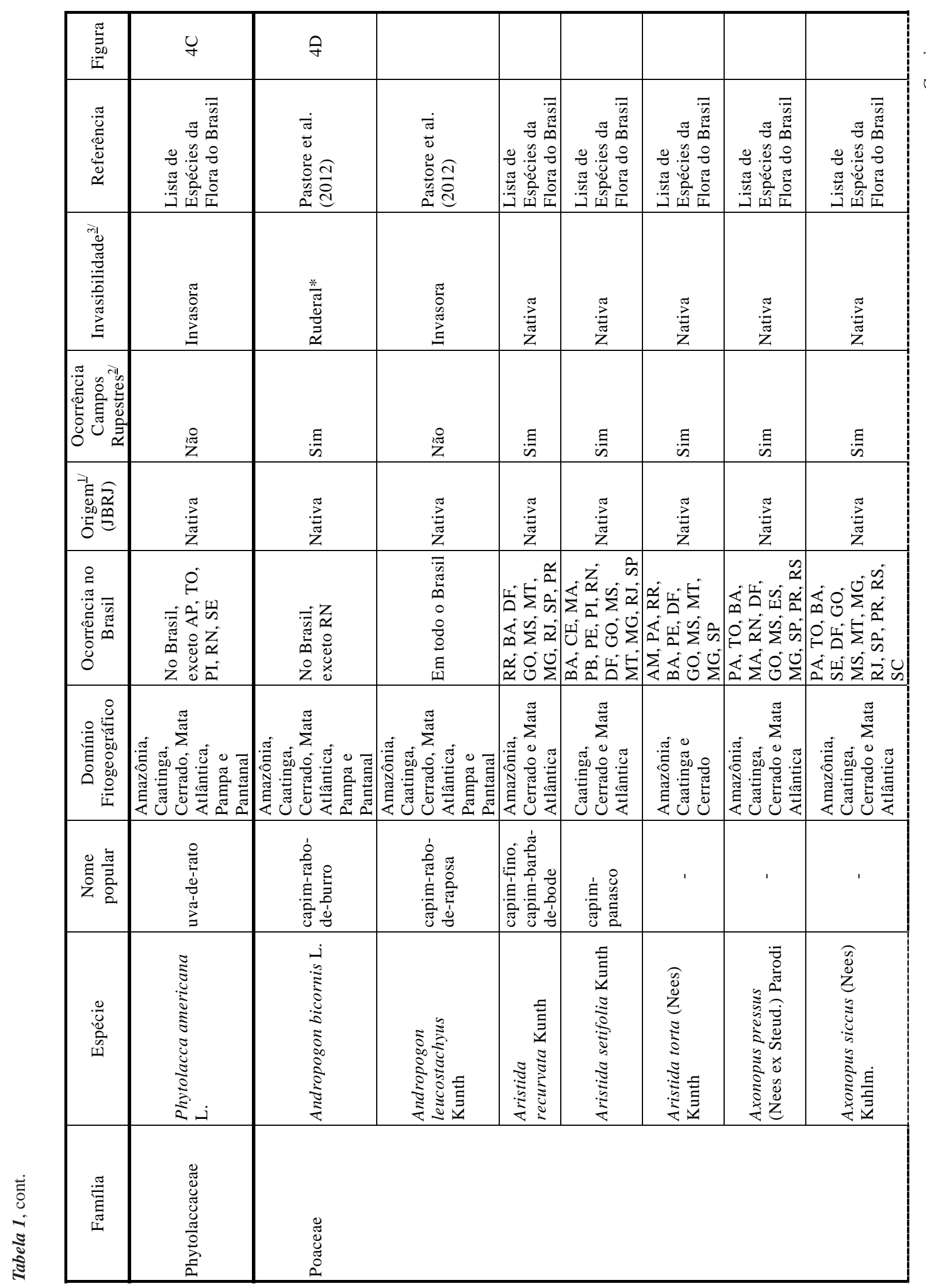




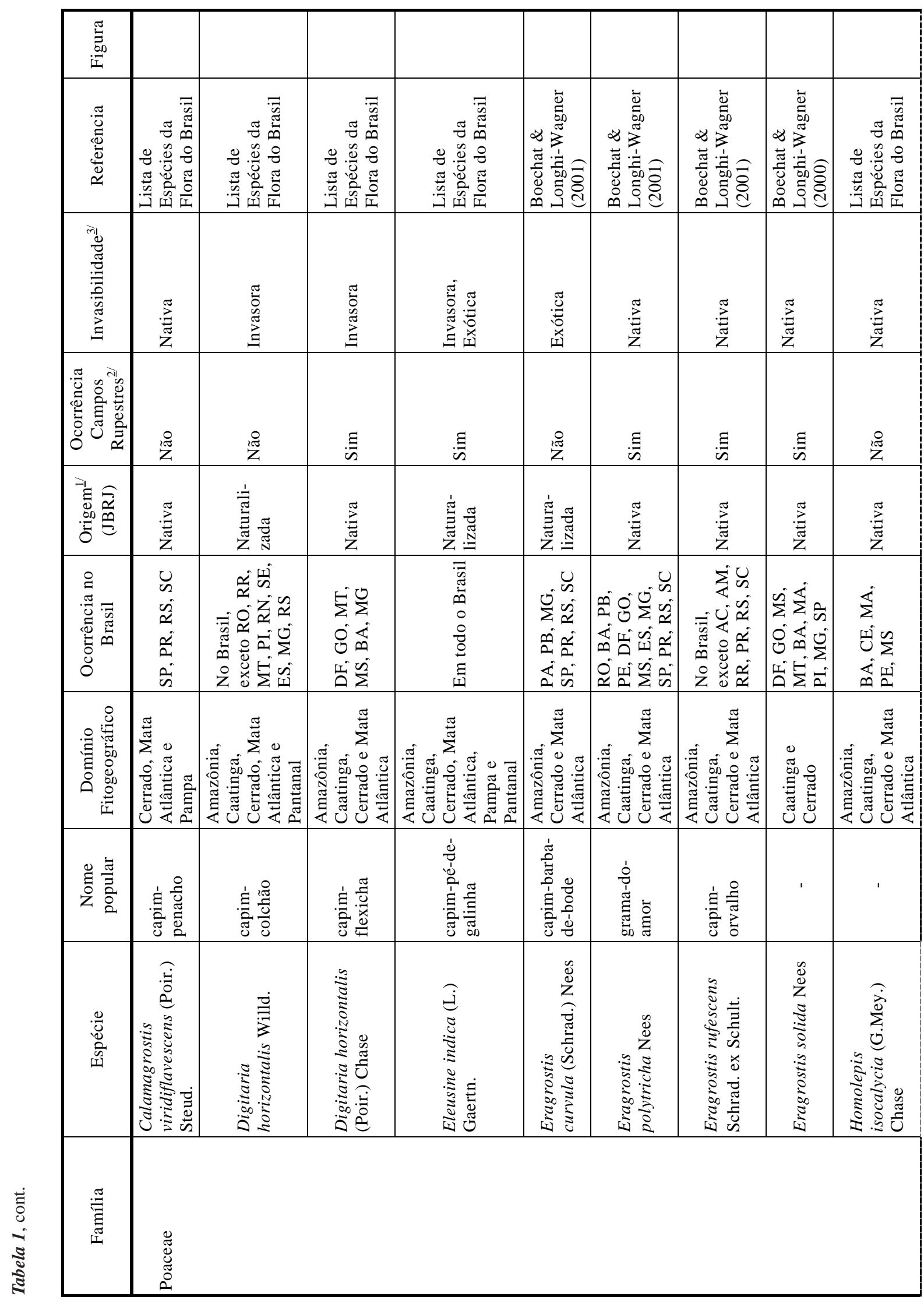




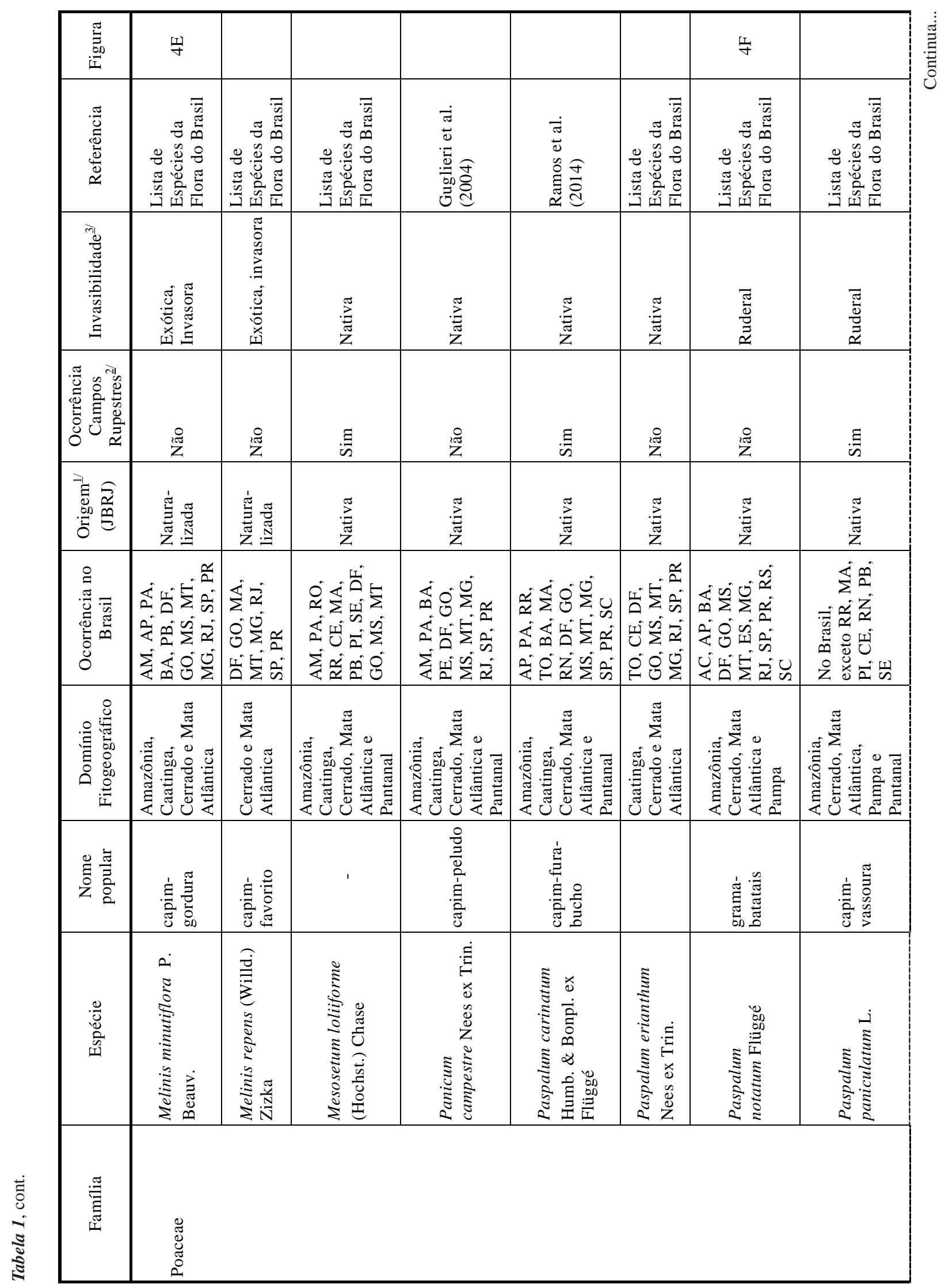




\begin{tabular}{|c|c|c|c|c|c|c|c|c|}
\hline 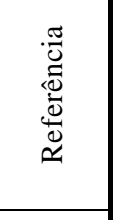 & 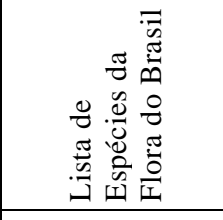 & 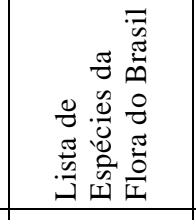 & 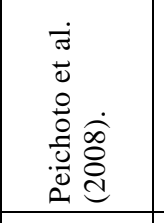 & 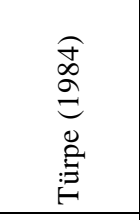 & 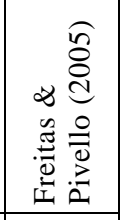 & 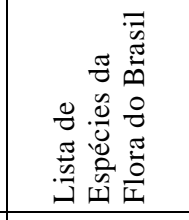 & 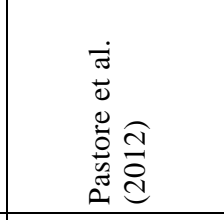 & 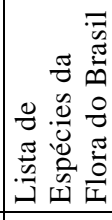 \\
\hline 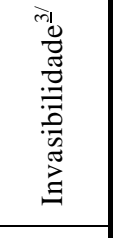 & 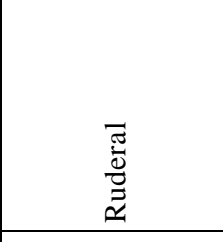 & 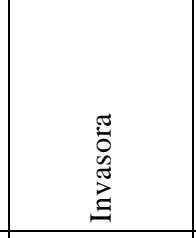 & 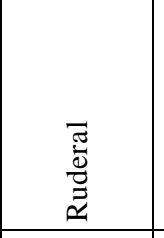 & $\stackrel{\overbrace{}}{\pi}_{Z}^{\pi}$ & $\begin{array}{l}\stackrel{\pi}{\pi} \\
Z\end{array}$ & 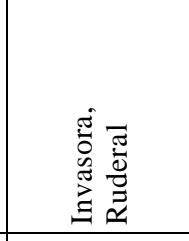 & 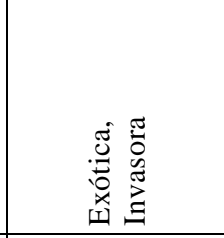 & $\begin{array}{l}\stackrel{\pi}{\mathbb{Z}} \\
\text { Z }\end{array}$ \\
\hline 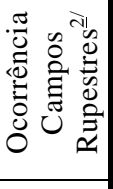 & 涪 & 思 & $\begin{array}{l}\stackrel{0}{\pi} \\
\end{array}$ & 㐘 & 涪 & 吾 & 击 & $\begin{array}{l}\stackrel{i}{\pi} \\
Z\end{array}$ \\
\hline 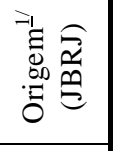 & $\begin{array}{l}\stackrel{\pi}{\pi} \\
Z\end{array}$ & 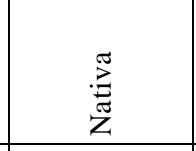 & $\begin{array}{l}\stackrel{\pi}{\pi} \\
Z\end{array}$ & $\begin{array}{l}\stackrel{\pi}{\pi} \\
Z \\
\end{array}$ & $\begin{array}{l}\stackrel{\pi}{\mathbb{\pi}} \\
Z \\
\end{array}$ & $\begin{array}{l}\stackrel{\pi}{\pi} \\
Z\end{array}$ & $\begin{array}{l}\stackrel{\pi}{\pi} \\
Z\end{array}$ & 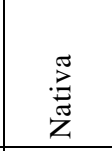 \\
\hline 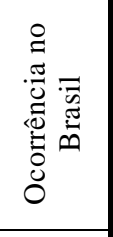 & 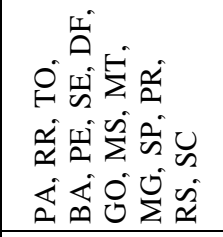 & 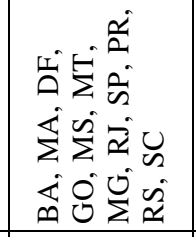 & 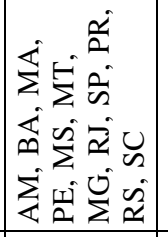 & 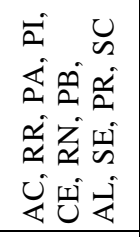 & 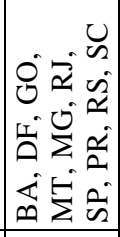 & 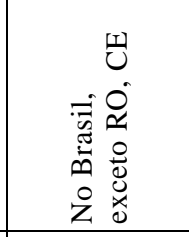 & 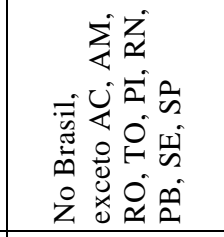 & $\begin{array}{l}\text { के } \\
\text { 这 }\end{array}$ \\
\hline 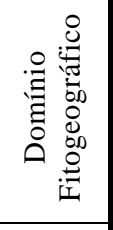 & 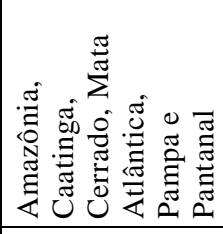 & 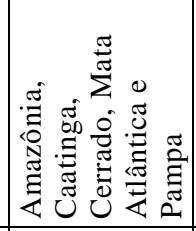 & 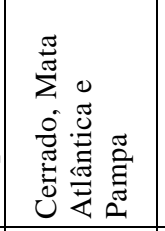 & 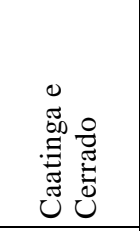 & 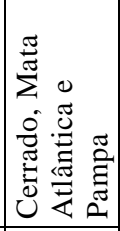 & 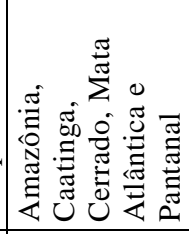 & 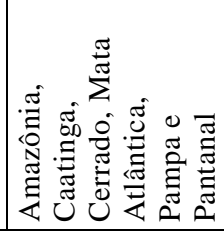 & 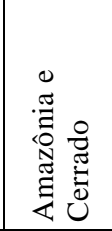 \\
\hline 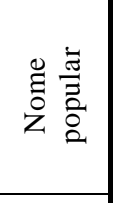 & 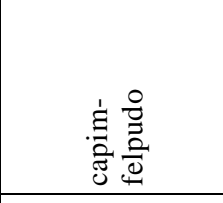 & 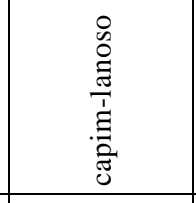 & 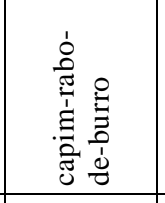 & & 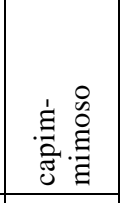 & 息营 & 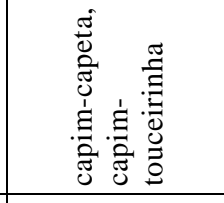 & \\
\hline 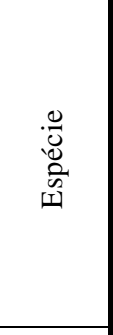 & 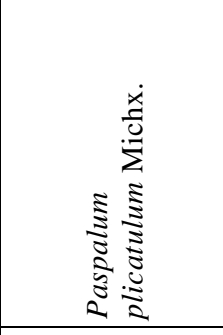 & 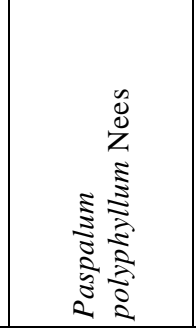 & 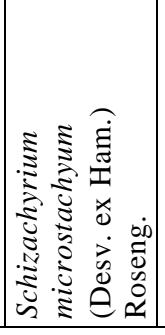 & 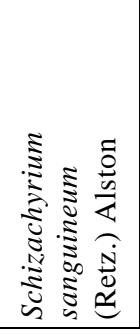 & 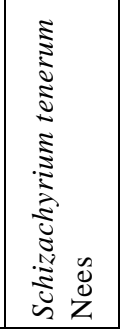 & 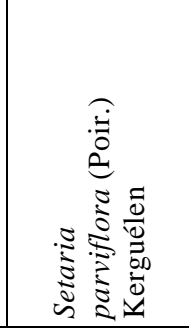 & 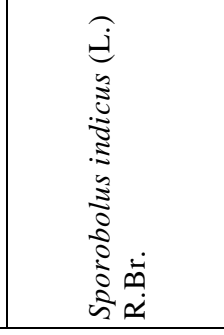 & 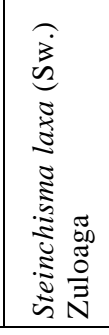 \\
\hline$\underset{\widetilde{\Xi}}{\stackrel{\pi}{\Xi}}$ & 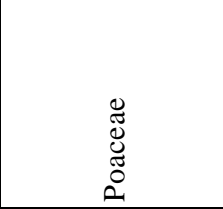 & & & & & & & \\
\hline
\end{tabular}




\begin{tabular}{|c|c|c|c|c|c|}
\hline 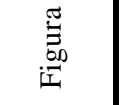 & & $\mathbb{\leftrightarrow}$ & & เึ & \\
\hline 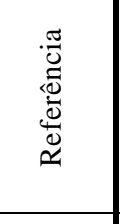 & 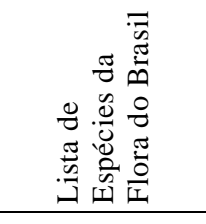 & 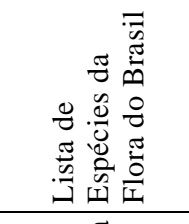 & 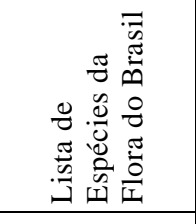 & 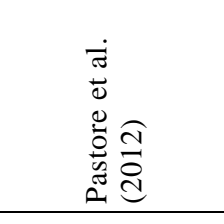 & 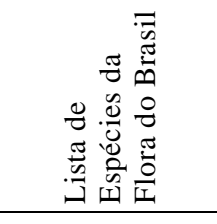 \\
\hline 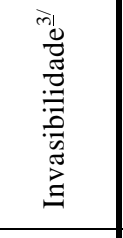 & $\begin{array}{l}\stackrel{\pi}{\pi} \\
\stackrel{\pi}{Z} \\
\end{array}$ & 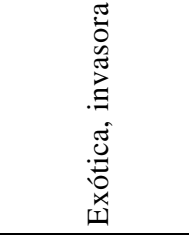 & $\stackrel{\substack{\pi \\
Z}}{Z}$ & 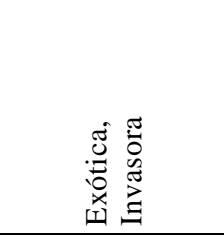 & 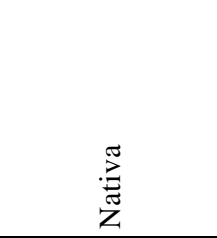 \\
\hline 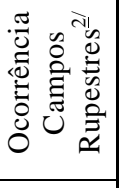 & 疍 & $\begin{array}{l}2 \pi \\
\text { Z }\end{array}$ & 帠 & 具 & $\underset{殳}{\stackrel{\pi}{Z}}$ \\
\hline 光 & 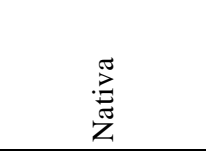 & 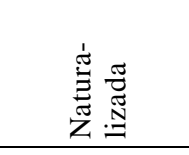 & 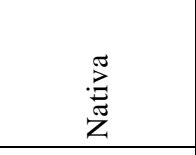 & $\begin{array}{l}\stackrel{\pi}{Z} \\
\stackrel{\pi}{Z} \\
\end{array}$ & $\begin{array}{l}\stackrel{\pi}{Z} \\
\text { Z } \\
\end{array}$ \\
\hline 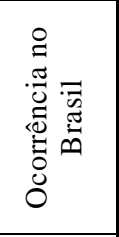 & 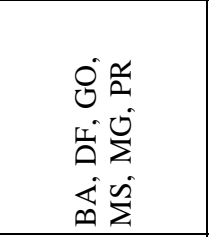 & 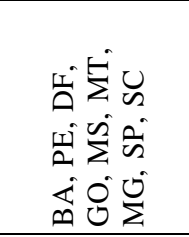 & 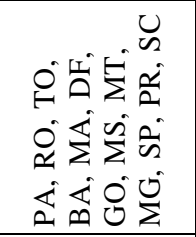 & 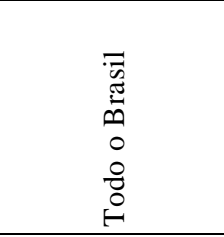 & 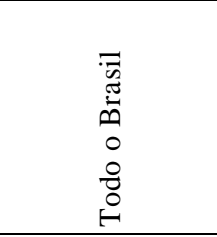 \\
\hline 兽 & 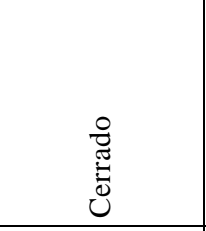 & 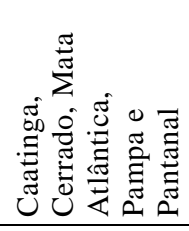 & 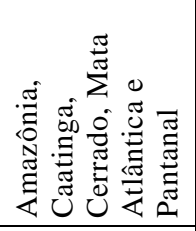 & 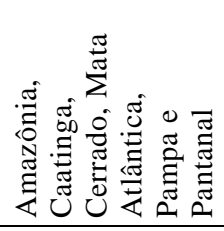 & 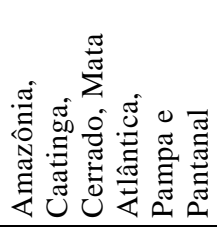 \\
\hline 号营 & & 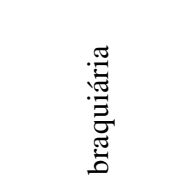 & 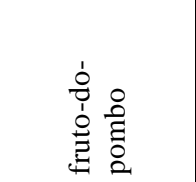 & 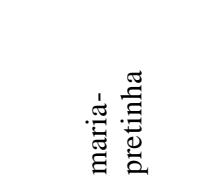 & 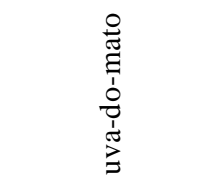 \\
\hline 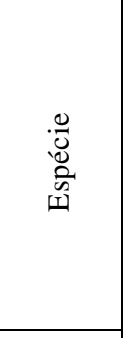 & 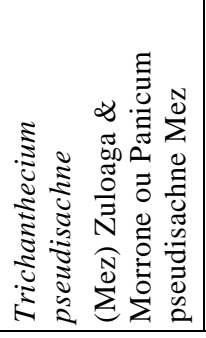 & 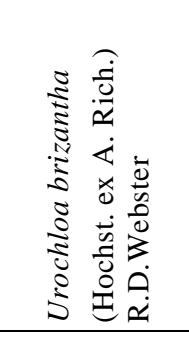 & 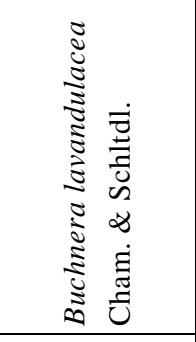 & 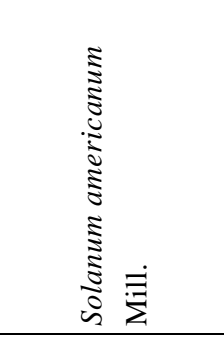 & 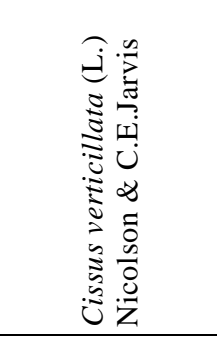 \\
\hline 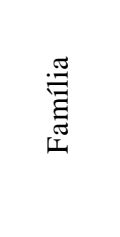 & 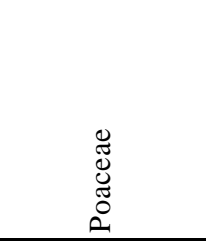 & & 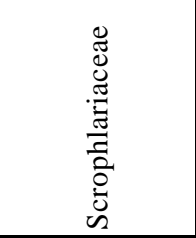 & 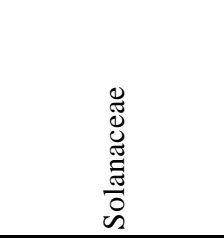 & 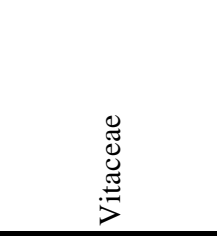 \\
\hline
\end{tabular}



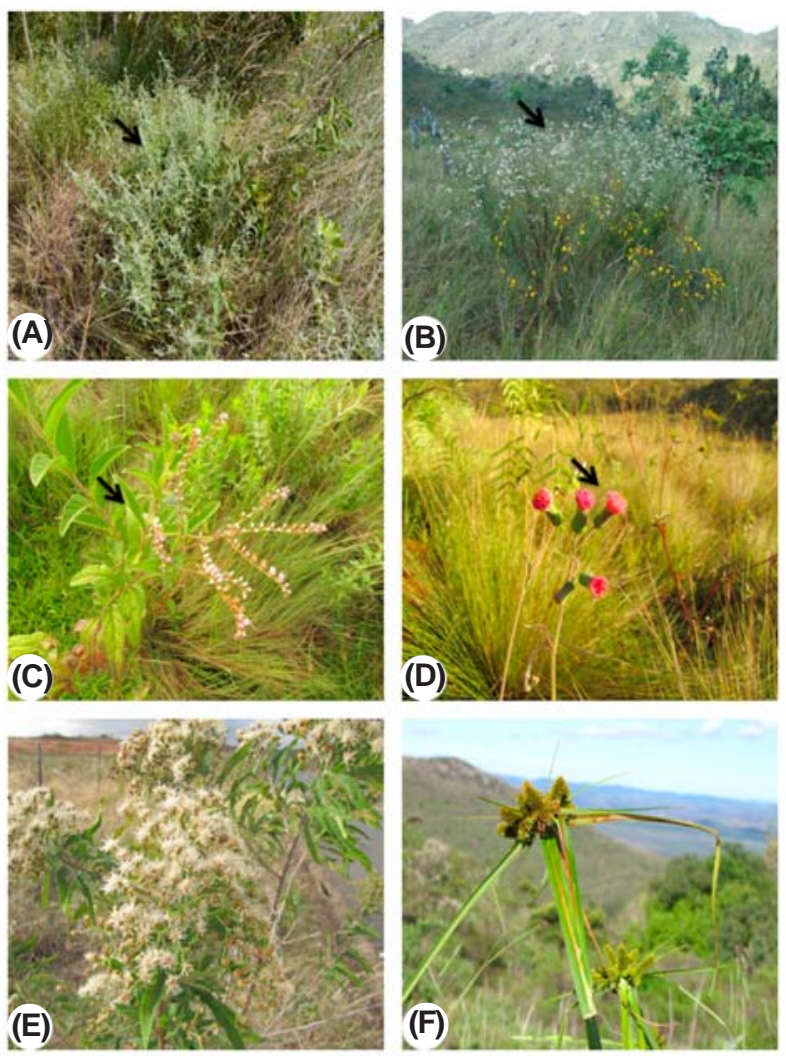

Figura 2 - Invasão biológica por espécies nativas, não nativas e exóticas em áreas restauradas do campo rupestre. (A) Achyrocline satureoides. (B) Ageratum fastigiatum. (C) Cyrtocymura scorpioides. (D) Emilia fosbergii. (E) Vernonanthura phosphorica. (F) Cyperus aggregatus.

Pivello et al. (1999). Nos campos rupestres, espécies de gramineas africanas vêm avançando rapidamente, e não há até o momento nenhum estudo aprofundado a respeito.

A família Fabaceae foi o segundo grupo estudado com maior número de representantes de espécies não nativas no campo rupestre (15 spp.), destacando-se as espécies reconhecidamente invasoras, como o feijãoguandu (Cajanus cajan) e a unha-de-gato (Mimosa pigra). Cajanus cajan é uma das espécies mais utilizadas na recuperação de áreas degradadas, e seu uso tem sido justificado para a melhoria do solo, já que suas raizes possuem simbiose com bactérias nitrificantes (Beltrame \& Rodrigues, 2007). O feijão-guandu foi usado para facilitar o processo de sucessão na restauração da rodovia MG-010 no ano de 2004, a fim de criar sombra
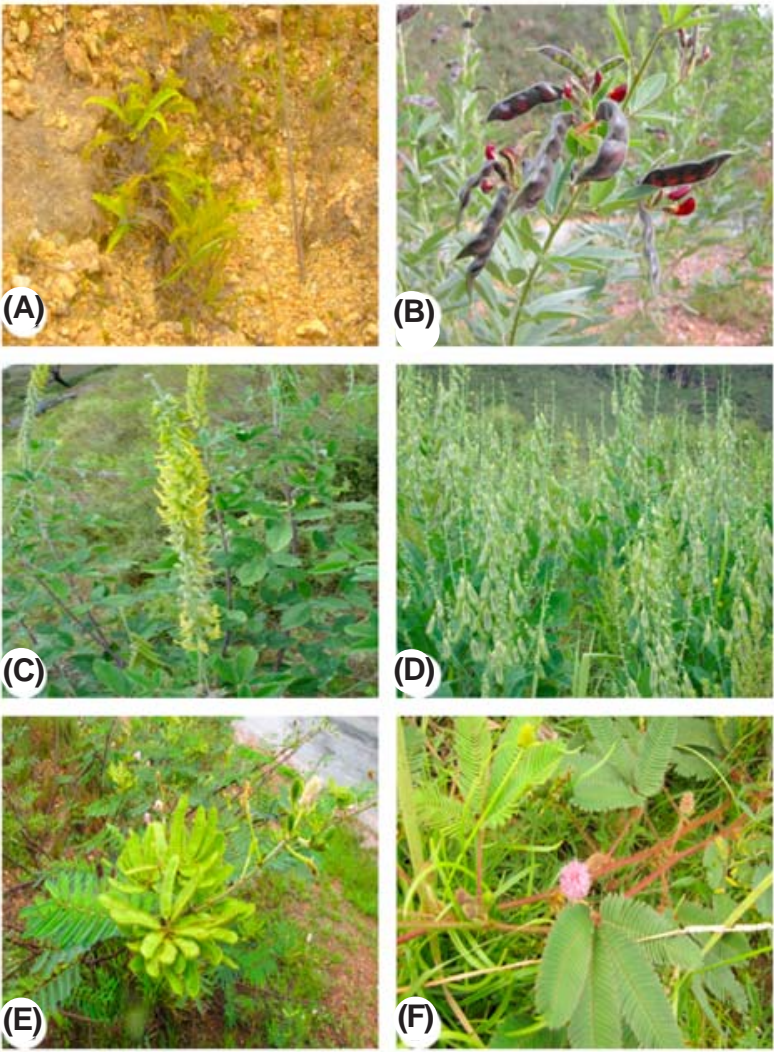

Figura 3 - Invasão biológica por espécies nativas, não nativas e exóticas em áreas restauradas do campo rupestre. (A) Pteridium arachnoideum. (B) Cajanus cajan. (C) Crotalaria pallida. (D) Crotalaria spectabilis. (E) Mimosa pigra. (F) Mimosa pudica.

para espécies nativas e também fornecer cobertura vegetal para o solo suscetível à erosão. Todavia, Hilário et al. (2011) mostraram que vários anos após a introdução de Cajanus cajan ainda se observava que, além de ela não fornecer sombra para outras espécies nativas nem proporcionar cobertura vegetal para as áreas erodidas, impedia a colonização natural das áreas restauradas. Além disso, estes autores mostraram que tal espécie começou a propagar-se além da área onde foram plantadas, invadindo as áreas adjacentes à rodovia. Assim, mostraram que Cajanus cajan afetava negativamente toda a comunidade de plantas que habitam os campos rupestres da Serra do Cipó. Outras leguminosas presentes nesta região, como Crotalaria pallida e Crotalaria spectabilis, são espécies altamente utilizadas para contenção de erosão em obras viárias e também como banco de 

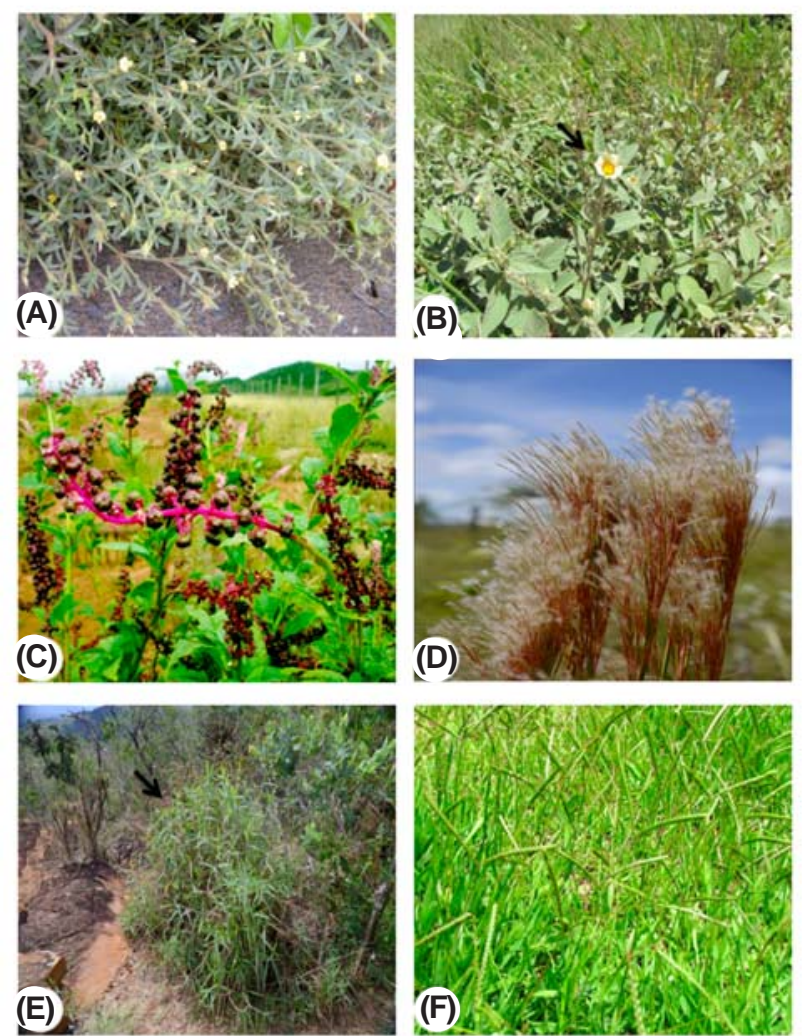

Figura 4 - Invasão biológica por espécies nativas, não nativas e exóticas em áreas restauradas do campo rupestre. (A) Stylosanthes guianensis. (B) Sida linifolia. (C) Phytolaca americana. (D) Andropogon bicornis. (E) Melinis minutiflora. (F) Paspalum notatum.

proteínas para a alimentação do gado. Outra espécie que tem apresentado grande desempenho é Mimosa pigra, popularmente conhecida como unha-de-gato. Esta espécie é bastante agressiva e produz grande quantidade de sementes, que se espalham prontamente em todos os habitats, incluindo áreas de proteção permanente, como nascentes e encostas. Observações casuais indicam também a preocupante colonização dos campos rupestres por espécies sabidamente nocivas, como Leucena leucocephala, Mimosa pudica e Cassia mangio, as quais devem ser monitoradas e erradicadas.

No terceiro grupo mais importante em número de espécies colonizadoras de áreas restauradas, as Asteraceae apresentam espécies bastante agressivas, como Acanthospermum australe, Achyrocline satureioides e Ageratum fastigiatum. Estas espécies têm invadido o campo rupestre, adentrando por mais de $4-5 \mathrm{~km}$ a partir da borda da rodovia. Entretanto, é provável que já tinham sido introduzidas há mais tempo nos campos rupestres.

A informação sobre novas ocorrências de espécies, em relação ao trabalho realizado por Giulietti et al. (1987) (principalmente ao longo das margens da rodovia MG 10), precisa ainda ser vista com cautela. Primeiramente, esses dados são seguramente conservadores, pois apenas as espécies encontradas nas áreas restauradas foram listadas, enquanto praticamente toda a margem da referida rodovia encontra-se tomada por espécies não nativas, ruderais e exóticas (Fernandes \& Barbosa, 2013) (Figura 5). Essas observações indicam
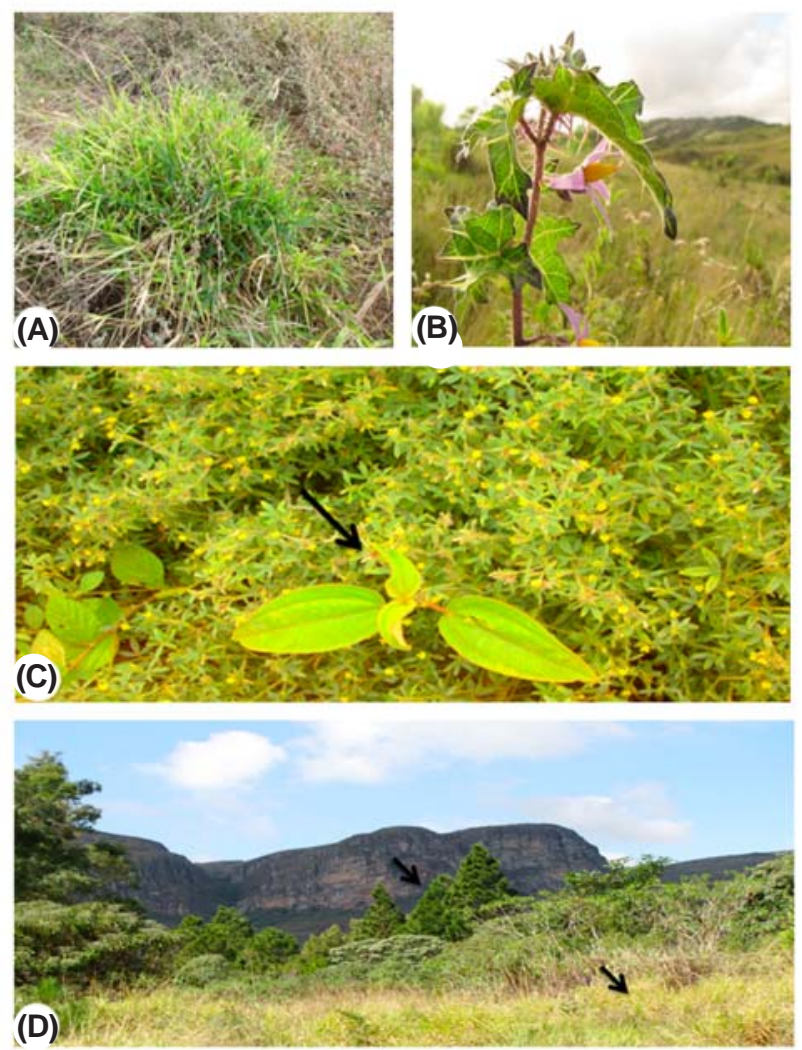

Figura 5 - Invasão biológica por espécies nativas, não nativas e exóticas em áreas restauradas do campo rupestre. (A) Urochloa brizantha. (B) Solanum maericanum. (C) Sombreamento de mudas de Tibouchina granulosa por Stylosanthes guianensis. (D) Modificação da paisagem natural dos campos rupestres ao longo da rodovia MG 10 por espécies introduzidas intencionalmente: Pinus sp. e Urochloa brizantha (setas). 
que vêm sendo registradas invasões recentes ou, pelo menos, durante os últimos 25 anos. Muitas dessas espécies, lamentavelmente, foram intencionalmente introduzidas para fins de restauração ambiental ao longo das rodovias ou mesmo em áreas de mineração, justamente em uma região de proteção ambiental federal (Barbosa \& Fernandes, 2008; Fernandes \& Barbosa, 2013). Grande parte dessas espécies representa grande ameaça à integridade dos campos rupestres e pode colocar em risco não apenas projetos de restauração, como todas as unidades de conservação da região e, também, proprietários particulares que têm como foco a conservação da paisagem e serviços ambientais naturais da região (Fernandes et al., 2014).

Observações de campo indicam que os eventos de invasão biológica carreados pelas espécies listadas neste estudo podem ser responsáveis pelo "início do fim" da vegetação singular dos campos rupestres na região (Fernandes \& Barbosa, 2013). Algumas espécies introduzidas já adentraram e se estabeleceram nos campos rupestres (Hilário et al., 2011). Algumas delas podem ser encontradas a mais de $2 \mathrm{~km}$ a partir da borda da rodovia asfaltada, incluindo $A$. fastigiatum, $M$. pigra, M. minutiflora, U. brizantha, A. satureioides, C. cajan, C. pallida e C. spectabilis, entre muitas outras. A Figura 5C mostra o abafamento de mudas da espécie nativa Tibouchina granulosa por Stylosanthes guianensis, enquanto a Figura 5D mostra uma área da Serra do Cipó com grande população de Pinus sp. e U. brizantha ao longo da rodovia MG 10.

A simples presença de espécies com histórico de invasão e danos já é um fator de preocupação, uma vez que muitas invasões de grande porte podem acontecer até 50 anos após a chegada dos primeiros propágulos à região invadida (Cox, 2004; Daehler, 2009). A ampliação na frequência de ocorrência, principalmente das espécies não nativas e exóticas em toda a região, é bastante preocupante em razão do rápido crescimento, abafamento e eliminação das espécies nativas. Apesar da inexistência de dados numéricos acerca das populações de espécies exóticas e invasoras não nativas e dos efeitos diretos na vegetação nativa, a existência dessa lista de espécies é de suma importância para a conservação dos campos rupestres, por fornecer dados pioneiros sobre as espécies potencialmente perigosas para esse ecossistema pouco resiliente. De acordo com Ziller e Galvão (2002), a grande maioria dos países carece tanto de registros como de medidas de prevenção e controle de espécies invasoras, requerendo coleta e organização de dados para retratar a situação atual e estabelecer prognósticos sobre o problema. Esse seria exatamente o caso do Brasil, que sofre com o problema, porém ainda não se conhecem suas reais dimensões. Espera-se que os resultados gerados neste trabalho sirvam como ferramenta para o desenvolvimento de futuros estudos e projetos de manejo das áreas degradadas e enriqueçam a literatura com dados precisos da real situação do estabelecimento de plantas invasoras nos campos rupestres dessas montanhas.

\section{AGRADECIMENTOS}

A J.C. Santos e J. Cortez-Almeida e dois revisores anônimos, pelas suas sugestões em versões antigas do manuscrito. Ao DER-MG, Planta LTDA, CNPq, FAPEMIG e Reserva Vellozia, pelo suporte financeiro e logístico.

\section{LITERATURA CITADA}

BARBOSA, N. P. U.; FERNANDES, G. W. A. A destruição do jardim. Sci. Am. Brasil, v. 79, n. 1, p. 82-84, 2008.

BARBOSA, N. P. U. et al. Distribution of non-native invasive species and soil properties in proximity to paved roads and unpaved roads in a quartzitic mountainous grassland of southeastern Brazil (rupestrian fields). Biol. Invasions, v. 12, n. 11, p. 3745-3755, 2010.

BARET, S. et al. Current distribution and potential extent of the most invasive alien plant species on La Re' union (Indian Ocean, Mascarene Islands). Aust. Ecol., v. 31, n. 6, p. 747-758, 2006.

BECHARA, F. C. et al. Quebra de dormência de sementes de Chamaecrista flexuosa (L.) Greene Leguminosae visando a restauração ecológica do Cerrado. R. Biol. Neotr., v. 4, n. 1, p. 58-63, 2007.

BELTRAME, T. P.; RODRIGUES, E. Feijão-guandu (Cajanus cajan (L.) Millsp.) na restauração de florestas tropicais. Semina: Ci. Agr., v. 28, n. 1, p. 19-28, 2007. 
BENITES, V. M. et al. Soil associated with rock outcrops in the Brazilian mountain ranges Mantiqueira and Espinhaço. R. Bras. Bot., v. 30, n. 4, p. 569-577, 2007.

BOECHAT, S. C.; LONGHI-WAGNER, H. M. Padrões de distribuição geográfica dos táxons brasileiros de Eragrostis (Poaceae, Chloridoideae). R. Bras. Bot., v. 23, n. 4, p. 177-194, 2000 .

BOECHAT, S. C.; LONGHI-WAGNER, H. M. O gênero Eragrostis (Poaceae) no Brasil. Iheringia. Série Bot., v. 55, n. 1, p. 23-169, 2001.

CARVALHO, F. et al. The mosaic of habitats in the highaltitude Brazilian rupestrian fields is a hotspot for arbuscular mycorrhizal fungi. Appl. Soil Ecol., v. 52, n. 1, p. 9-19, 2012.

CHRISTEN, D.; MATLACK, G. The role of roadsides in plant invasions: a demographic approach. Conserv. Biol., v. 20, n. 2, p. 385-391, 2006.

COMÉRIO, E. F. et al. Influência de plantas invasoras na abundância de himenópteros parasitoides (insecta, Hymenoptera) coletados em cultura de coqueiro anão verde, em linhares, ES, Brasil. Arq. Inst. Biol., v. 80, n. 1, p. 117-123, 2013.

COUTINHO, L. M. Fire in the ecology of the Brazilian cerrado. In: GOLDAMMER, J. G. (Ed). Fire in the tropical biota. New York: Springer, 1990. p. 82-105.

(Ecological Studies, 84)

COX, G. W. Alien species and evolution. Washington: Island Press, 2004. 400 p.

D’ANTONIO, C.; MEYERSON L. A. Exotic plant species as problems and solutions in ecological restoration: A synthesis. Rest. Ecol., v. 10, n. 4, p. 703-713, 2002.

DAEHLER, C. C. Short lag times for invasive tropical plants: evidence from experimental plantings in Hawai'i. PLoS One, v. 4, n. 2, p. e4462, 2009.

DIETZ, H. et al. MIREN: A new research network concerned with plant invasion into mountain areas. Mount. Res.

Develop., v. 26, n. 1, p. 80-81, 2006.

FERNANDES, G. W.; BARBOSA, N. P. U. Bombas-relógio que ameaçam a natureza. Sci. Am. Brasil, v. 135, n. 1, p. 60-61, 2013.

FERNANDES, G.W. et al. Challenges for the conservation of vanishing megadiverse rupestrian grasslands. Natur. \& Cons. v. 12, n. 2, p. 162-165, 2014.

FONSECA, R. L. et al. Predicting invasive potential of smooth Crotalaria (Crotalaria pallida) in Brazilian national parks based on African records. Weed Sci., v. 54, n. 3, p. 458-463, 2006.
FREITAS, K. G.; PIVELLO, V. R. A ameaça das gramíneas exóticas à biodiversidade. In: PIVELLO, V. R.; VARANDA, E. M. (Org.). O cerrado pé-de-gigante (parque estadual de Vassununga, SP) - ecologia e conservação. São Paulo: Secretaria de Estado do Meio Ambiente, 2005. p. 283-296.

FULLER, P. L. et al. Non-indigenous fishes introduced into inland waters of the United States. Bethesda: American Fisheries Society, 1999. 622 p.

GIULIETTI, A. M. et al. Flora da Serra do Cipó, Minas Gerais: Caracterização e lista das espécies. B. Bot. USP, v. 9, n. 1, p. 1-151, 1987.

GREENBERG, C. H. et al. Roadside soil: a corridor for invasion of xeric scrub by nonindigenous plants. Nat. Areas J., v. 17, n. 1, p. 99-109, 1997.

GUGLIERI, A. et al. Synopsis of Panicum subg. Panicum (Poaceae, Paniceae) in Brazil. Acta Bot. Bras., v. 18, n. 2, p. 359-367, 2004.

GUGLIERI-CAPORAL, A. et al. Flora invasora de cultivos de aveia-preta, milho e sorgo em região de cerrado do Estado de Mato Grosso do Sul, Brasil. Bragantia, v. 70, n. 2, p. 247-254, 2011.

HEFLER, S. M. Novidades taxonômicas em espécies de Cyperus subg. Cyperus (Cyperaceae). Rodriguésia, v. 61, p. S07-S14, 2010.

HILÁRIO, R. R. et al. Unexpected effects of pigeon-peas (Cajanus cajan) in the restoration of rupestrian fields. Planta Daninha, v. 29, n. 4, p. 717-723, 2011.

HOROWILTZ, C. et al. Flora exótica no Parque Nacional de Brasília: Levantamento e classificação das espécies. Biodiver. Bras., v. 3, n. 1, p. 50-73, 2013.

HUGHES, F.; VITOUSEK, P. M. Barriers to shrub reestablishment following fire in seasonal submontane woodland in Hawaii. Oecologia, v. 93, n. 4, p. 557-563, 1993.

HULME, P. E. Beyond control: wider implications for the management of biological invasions. J. Appl. Ecol., v. 43, n. 5, p. 835-847, 2006.

IRWIN, H. S.; BARNEBY, R. C. The american Cassiinae: a synoptical revision of the Leguminosae tribe Cassieae subtribe Cassiinae in the New World. Memoirs New York Bot. Garden, v. 35, p. 2, 1982.

KGOPE, B. S. et al. Growth responses of African savanna trees implicate atmospheric $\left[\mathrm{CO}^{2}\right]$ as a driver of past and current changes in savanna tree cover. Aust. Ecol., v. 35, p. 451-463, 2010. 
KÜFFER, C. et al. The mountain invasion research network (MIREN). Mountain Res. Initiative Newsl., v. 1, n. 1, p. 12-14, 2008.

LONSDALE, W. M.; LANE, A. M. Tourist vehicles as vectors of weed seeds in Kakadu National Park, northern Australia. Biol. Conserv., v. 69, n. 3, p. 277-283, 1994.

Lista de espécies da flora do Brasil. Jardim Botânico do Rio de Janeiro. Disponível em: <http://www.jbrj.gov.br/>. Acesso em: 20 jan. 2014.

MACK, M. C. et al. Biotic invasions: causes, epidemiology, global consequences, and control. Ecol. Appl., v. 10, n. 3, p. 689-710, 2000.

MADEIRA, J. A.; FERNANDES, G. W. Reproductive phenology of sympatric taxa of Chamaecrista (Leguminosae) in Serra do Cipó, Brazil. J. Trop. Ecol., v. 15, n. 4, p. 463-479, 1999.

MARTINELLI, G. Mountain biodiversity in Brazil. R. Bras. Bot., v. 30, n. 4, p. 587-597, 2007.

NARDOTO, G. B. et al. Nutrient use efficiency at ecosystem and species level in savanna areas of Central Brazil and impacts off fire. J. Trop. Ecol., v. 22, n. 1, p. 191-201, 2006.

NEGREIROS, D. et al. Seedling growth and biomass allocation of endemic and threatened shrubs of rupestrian fields. Acta Oecol., v. 35, n. 2, p. 301-310, 2009.

NEGREIROS, D. et al. Caracterização fisico-quimica de solos quartzíticos degradados e áreas adjacentes de campo rupestre na Serra do Cipó, MG, Brasil. Neotr. Biol. Conserv., v. 6, n. 3, p. 156-161, 2011.

PARSONS, J. J. Spread of African pasture grasses to the American tropics. J. Range Manage., v. 25, n. 1, p. 12-17, 1972.

PASTORE, M. et al. Plantas exóticas invasoras na reserva biológica do alto da serra de Paranapiacaba, Santo André - SP. Guia de campo. São Paulo: Instituto de Botânica, 2012.

PAUCHARD, A. et al. Ain't no mountain high enough: plant invasions reaching new elevations. Front. Ecol. Environ., v. 7, n. 9, p. 479-486, 2009.

PEICHOTO, M. C. et al. Morphometric analysis of Schizachyrium condensatum (Poaceae) and related species. Plant System. Evol., v. 276, n. 3-4, p. 177-189, 2008.

PIMENTEL, D. et al. Economic and environmental threats of alien plant, animal, and microbe invasions.

Agric.Ecosyst.Environ., v. 84, n. 1, p. 1-20, 2001.
PIVELLO, V. R. et al. Abundance and distribution of native and invasive alien grasses in a “cerrado' (Brazilian savanna) biological reserve. Biotropica, v. 31, n. 1, p. 71-82, 1999.

RAMOS, D. M. et al. Habitat ûltering and interspeciûc competition inûuence phenological diversity in an assemblage of neotropical savanna grasses. Braz. J. Bot., v. 37, n. 1, p. 29-36, 2014.

REJMÁNEK, M. et al. Plant invasions and invasibility of plant communities. 2.ed. Vegetation ecology. Oxford: Blackwell Science, 2005. p. 332-355.

RICHARDSON, D. M.; PYSEK, P. Fifty years of invasion ecology - the legacy of Charles Elton. Diverv. Distrib., v. 14, n. 2, p. 161-168, 2008.

ROUGET, M. et al. Current patterns of habitat transformation and future threats to biodiversity in the cape floristic region, South Africa. Biol. Conserv., v. 112, n. 1, p.63-85, 2003.

SILVA, J. S. O.; HARIDASAN, M. Acúmulo de biomassa aérea e concentração de nutrientes em Melinis minutiflora P. Beauv. e gramíneas nativas do cerrado. R. Bras. Bot., v. 30, n. 2, p. 337-344, 2007.

SILVA MATOS, D. M.; BELINATO, T. A. Interference of Pteridium arachnoideum (Kaulf.) Maxon. (Dennstaedtiaceae) on the establishment of rainforest trees. Braz. J. Biol., v. 70, n. 2, p. 311-316, 2010.

SIMBERLOFF, D. How much information on population biology is needed to manage introduced species? Conserv. Biol., v. 17, n. 1, p. 3-92, 2003.

TILMAN, D. How productivity limits colonization and species richness in grasslands. Ecology, v. 74, n. 8, p. 2179-2191, 1993.

TILMAN, D. Community invasibility, recruitment limitation, and grassland biodiversity. Ecology, v. 78, n. 1, p. 81-92, 1997.

TROMBULAK, S. C.; FRISSELL, C. A. Review of ecological effects of roads on terrestrial and aquatic communities.

Conserv. Biol., v. 14, n. 1, p. 18-30, 2000.

TÜRPE, A. M. Revision of the South American species of Schizachyrium (Gramineae). Kew Bull., v. 39, n. 1, p. 169-169, 1984.

VIANA, L. R. et al. Ecological road threatens endemic Brazilian plant with extinction. Plant Talk, v. 41, n. 15, p. 15, 2005.

ZILLER, S. T.; GALVÃO, F. A. A degradação da estepe gramíneo-lenhosa no Paraná por contaminação biológica de Pinnus elliottii e P. taeda. Floresta, v. 32, n. 1, p. 41-47, 2002. 